\title{
Fighting Ebola with novel spore decontamination technologies for the military
}

\section{Christopher J. Doona ${ }^{1 *}$, Florence E. Feeherry ${ }^{1}$, Kenneth Kustin ${ }^{2}$, Gene G. Olinger ${ }^{3}$, Peter Setlow ${ }^{4}$, Alexander J. Malkin ${ }^{5}$ and Terrance Leighton ${ }^{6}$}

${ }^{1}$ U.S. Army Natick - Soldier RD\&E Center, Warfighter Directorate, Natick, MA, USA, ${ }^{2}$ Department of Chemistry, Emeritus, Brandeis University, Waltham, MA, USA, ${ }^{3}$ National Institute of Allergy and Infectious Diseases, Integrated Research Facility Division of Clinical Research, Fort Detrick, MD, USA, ${ }^{4}$ Department of Molecular Biology and Biophysics, University of Connecticut Health Center, Farmington, CT, USA, ${ }^{5}$ Biosciences and Biotechnology Division, Physical and Life Sciences Directorate, Lawrence Livermore National Laboratory, Livermore, CA, USA, ${ }^{6}$ Children's Hospital - Oakland Research Institute, University of California San Francisco - Benioff, Oakland, CA, USA

Recently, global public health organizations such as Doctors without Borders (MSF), the World Health Organization (WHO), Public Health Canada, National Institutes of Health $(\mathrm{NIH})$, and the U.S. government developed and deployed Field Decontamination

OPEN ACCESS

Edited by:

Alexander Mathys, German Institute of Food Technologies, Germany

Reviewed by:

Bei Li,

Hubei University of Medicine, China Bastian Dörrbecker, German Institute of Food Technologies, Germany

*Correspondence:

Christopher J. Doona, U.S. Army Natick - Soldier RD\&E

Center, Warfighter Directorate,

Kansas Street, Natick,

MA 01760-5018, USA

christopher.j.doona.civ@mail.mil

Specialty section: This article was submitted to

Food Microbiology,

a section of the journal

Frontiers in Microbiology

Received: 30 March 2015

Accepted: 17 June 2015

Published: 12 August 2015

Citation:

Doona CJ, Feeherry FE, Kustin K,

Olinger GG, Setlow P, Malkin AJ and Leighton T (2015) Fighting Ebola with novel spore decontamination

technologies for the military.

Front. Microbiol. 6:663.

doi: 10.3389/fmicb.2015.00663
Kits (FDKs), a novel, lightweight, compact, reusable decontamination technology to sterilize Ebola-contaminated medical devices at remote clinical sites lacking infrastructure in crisis-stricken regions of West Africa (medical waste materials are placed in bags and burned). The basis for effectuating sterilization with FDKs is chlorine dioxide $\left(\mathrm{ClO}_{2}\right)$ produced from a patented invention developed by researchers at the US Army Natick Soldier RD\&E Center (NSRDEC) and commercialized as a dry mixedchemical for bacterial spore decontamination. In fact, the NSRDEC research scientists developed an ensemble of $\mathrm{ClO}_{2}$ technologies designed for different applications in decontaminating fresh produce; food contact and handling surfaces; personal protective equipment; textiles used in clothing, uniforms, tents, and shelters; graywater recycling; airplanes; surgical instruments; and hard surfaces in latrines, laundries, and deployable medical facilities. These examples demonstrate the far-reaching impact, adaptability, and versatility of these innovative technologies. We present herein the unique attributes of NSRDEC's novel decontamination technologies and a Case Study of the development of FDKs that were deployed in West Africa by international public health organizations to sterilize Ebola-contaminated medical equipment. FDKs use bacterial spores as indicators of sterility. We review the properties and structures of spores and the mechanisms of bacterial spore inactivation by $\mathrm{ClO}_{2}$. We also review mechanisms of bacterial spore inactivation by novel, emerging, and established non-thermal technologies for food preservation, such as high pressure processing, irradiation, cold plasma, and chemical sanitizers, using an array of Bacillus subtilis mutants to probe mechanisms of spore germination and inactivation. We employ techniques of highresolution atomic force microscopy and phase contrast microscopy to examine the effects of $\gamma$-irradiation on bacterial spores of Bacillus anthracis, Bacillus thuringiensis, and Bacillus atrophaeus spp. and of $\mathrm{ClO}_{2}$ on $B$. subtilis spores, and present in detail assays using spore bio-indicators to ensure sterility when decontaminating with $\mathrm{ClO}_{2}$.

Keywords: Ebola, decontamination technologies, spores, chrloine dioxide, military medicine 


\section{Introduction}

Innovation in Science and Technology comes from myriad sources, such as thinking outside-the-box, applying expertise to new areas, or adapting novel technologies that advance the frontiers of knowledge to fill needs in the commercial marketplace for consumers or to meet critical capability gaps on the battlefield. Researchers at the U.S. Army Natick Soldier Research, Development and Engineering Center (NSRDEC) have invented and patented (Doona et al., 2014) an ensemble of novel decontamination technologies (Table 1) involving innovative dry, mixed-chemical technologies designed to be lightweight, compact, portable, easy-to-carry, energyindependent, flameless, almost waterless, inexpensive, safe to end-users and the environment ("green" technologies), and effective in addressing a diverse array of decontamination applications in far-forward military deployments or other high-intensity, austere environments by using the disinfectant chlorine dioxide $\left(\mathrm{ClO}_{2}\right)$. These characteristics also make NSRDEC's novel decontamination technologies well-suited for use during large-scale emergencies, natural disasters (Hurricane Katrina, tsunamis, superstorm Sandy) or in humanitarian relief in third-world countries.

The use of chlorine dioxide $\left(\mathrm{ClO}_{2}\right)$ to decontaminate Bacillus anthracis spores (causative agent of 'Anthrax') following the letter attacks on Washington, DC and other locations was facilitated by data from the author's laboratories and other studies. These attacks were unprecedented in their use of mail processing delivery systems to create large-scale and widearea $B$. anthracis spore contamination. They highlighted the need for more efficacious, agile and adaptive decontamination modalities that could extinguish primary and secondary nosocomial contact and transmission hazards. Concerns regarding transmission control of existential nosocomial diseases were further highlighted by the SARS and H1N1 pan epidemics. As Joshua Lederberg presciently observed in 1998 (profiles.nlm.nih.gov/ps/access/BBBDLP.pdf), with modern transportation and distribution infrastructure no infectious disease is more than 24 away from any location on the earth. Dr. Lederberg's insight became salient with the emergence of the Ebola crisis emanating from West Africa and the concomitant challenges of controlling secondary chains of transmission

TABLE 1 | Acronyms and attributes of NSRDEC decontamination technologies.

\begin{tabular}{|c|c|c|}
\hline Acronym & Technology & Attributes \\
\hline NCC & $\underline{\text { Novel }} \underline{\text { Chemical }}$ Combination & Dry powders mix with water \\
\hline PCS & 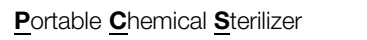 & Plastic suitcase sterilizer \\
\hline D-FENS & $\begin{array}{l}\text { Disinfectant-sprayer } \text { For } \\
\text { ENvironmentally friendly } \\
\underline{\text { Sanitation }}\end{array}$ & Collapsible handheld sprayer \\
\hline D-FEND ALL & $\begin{array}{l}\text { Disinfectant For ENvironmentally } \\
\text { friendly Decontamination, } \\
\text { ALL-purpose }\end{array}$ & All purpose decontamination \\
\hline CoD & 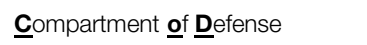 & In-package disinfectant \\
\hline FDK & Field Decontamination Kit & Ebola disinfectant \\
\hline
\end{tabular}

at their origin and globally. In the summer of 2014, global public health and medical personnel adapted NSRDEC's novel decontamination technologies for field use to fight the spread of Ebola by decontaminating medical equipment at remote clinical sites in West Africa.

Ebola virus disease (EVD) is a severe and often fatal disease in humans that is communicated between humans through contact with infected blood, organs or tissues, bodily fluids (saliva, sweat, vomit, urine, semen, and breast milk), or items they contaminate (clothing, bedding, gauze, needles and syringes, and medical equipment). In March, 2015, WHO estimated 24,842 cases and 10,299 deaths from this outbreak (World Health Organization [WHO], 2015a), and concerns of EVD heightened as EVD cases spread internationally. As an enveloped virus one with a lipid and protein membrane - Ebola is vulnerable to chemical disinfectants, such as household bleach $\left(\mathrm{OCl}^{-}\right)$ and chlorine dioxide $\left(\mathrm{ClO}_{2}\right)$, which can be used to sanitize infected surfaces, patient rooms, and to sterilize contaminated medical equipment at remote clinical sites in West Africa (World Health Organization [WHO], 2014). In parts of the world that consume non-traditional foods (bats, monkeys, bush meat) as protein sources, basic food hygiene for preventing the transmission of biological hazards apply equally well to the Ebola virus (Anelich and Moy, 2014; World Health Organization [WHO], 2015b): Keep clean, Separate raw and cooked, Cook thoroughly (specifically, boiling for $5 \mathrm{~min}$ or heating for $60 \mathrm{~min}$ at $T=60^{\circ} \mathrm{C}$ inactivates the Ebola virus - Anelich and Moy, 2014), Keep food at safe temperatures, and Use safe water and raw materials.

Natick Soldier RD\&E Center's ensemble of patented novel decontamination technologies have the acronyms NCC, PCS, D-FENS, D-FEND ALL, and CoD (Table 1) and feature a variety of embodiments designed to produce $\mathrm{ClO}_{2}$ for killing bacterial spores (B. anthracis), vegetative pathogens (Listeria monocytogenes, Escherichia coli, etc.), viruses (Ebola), and bacteriophage in cross-cutting applications (Setlow et al., 2009), such as sterilizing surgical instruments, decontaminating textiles (uniforms, tents, shelters), sanitizing fresh fruits and vegetables procured in host nations, disinfecting wastewater, providing potable water quality and safety, and promoting hygiene by decontaminating surfaces bathrooms, showers, laundries, Army Field Kitchens, Navy Galleys, and deployable medical units. Deployments of military personnel worldwide generate thousands of tons of wastewater and food waste annually that support disease vectors capable of adversely affecting human health and account for Disease and Non-Battle Injuries (DNBIs) that at an average rate of $1.5 \%$ of assigned personnel, would have cost all branches of the military an estimated $\$ 32.5 \mathrm{M}$ annually (300 personnel per day) during the time of the Balkan conflicts in the 1990s! Finding inexpensive, convenient, and effective decontamination technologies improves hygiene and reduces incidences of DNBIs and other foodborne illnesses, thereby saving all branches of the military millions of dollars in medical costs and promoting health and well-being. For innovative patents such as these, Thomson Reuters in 2012 named the U.S. Army among the Top 100 Global Innovators (Foran, 2013 - available at http://www.army.mil/article/99816/). 
Other technologies that decontaminate with gaseous $\mathrm{ClO}_{2}$ include electrically powered equipment to decontaminate facemasks worn as personal protective equipment (PPE) by emergency first-responders (Stubblefield and Newsome, 2015), and now Field Decontamination Kits (FDKs). FDKs are adapted from the commercial-off-the-shelf (COTS) version of NRDEC's decontamination technologies and are presently being used by global public health organizations [Doctors without Borders (MSF), World Health Organization (WHO), Public Health Canada, National Institutes of Health (NIH)] and the U.S. government to sterilize Ebola-contaminated medical equipment at remote clinical sites in West Africa. While the Ebola virus is classified as Biosafety level 4 (BSL-4) due to the severity of disease in humans, the Ebola virus itself is relatively fragile and presently without a standard test assay under representative conditions even in a high-level containment facility. Bacterial spores therefore provide the standard test assay for sterility and/or decontamination efficacy, primarily because bacterial spores exhibit more resistance to chemical and physical decontamination methods. The author's laboratories have studied the processes of Bacillus sporulation, spore germination, spore resistance and persistence, spore decontamination and spore structural biology for many years. Accordingly, we review bacterial spore properties, structures, and resistance mechanisms and focus on the mechanisms through which $\mathrm{ClO}_{2}$ inactivates bacterial spores as the indicators of efficient bio-decontamination.

We present the ontogeny of NSRDEC's novel $\mathrm{ClO}_{2}$ decontamination technologies for spores that evolved to field-ready FDKs to meet an urgent need in protecting healthcare workers in West Africa from the spread of EVD during the heights of this international public health crisis. And just as $\mathrm{ClO}_{2}$ is also a non-thermal food processing technology for sanitizing fresh fruits and vegetables, we explore the characteristics of other Non-thermal technologies (chemical sanitizers, high pressure, irradiation, heat, plasmas, and UV light), particularly high pressure and $\gamma$-irradiation, that have also been used in the decontamination of $B$. anthracis (Cléry-Barraud et al., 2004) or other types of spores, and we also consider the mechanisms of bacterial spore inactivation by these agents. The ability of $\mathrm{ClO}_{2}$ to kill spores used as bio-indicators of sterility is also examined in detail, and we use high-resolution Atomic Force Microscopy (AFM) and phase contrast microscopy to examine the effects of nonthermal technologies on bacterial spores (Figure 1).

\subsection{Additional Reference Materials}

More information relating to this manuscript is available through the following links:

a. http://www.necn.com/news/new-england/Mass-ResearchersCreate-Disinfectant-to-Fight-Ebola-280284792.html

b. http://www.metrowestdailynews.com/article/20141029/ NEWS/141025763/0/SEARCH http://www.wcvb.com/news/natick-labs-innovation-couldhelp-prevent-spread-of-ebola/29370460?utm_source= hootsuite\&utm_medium $=$ facebook\&utm_campaign $=w c v b$ \%2Bchannel\%2B5\%2Bboston

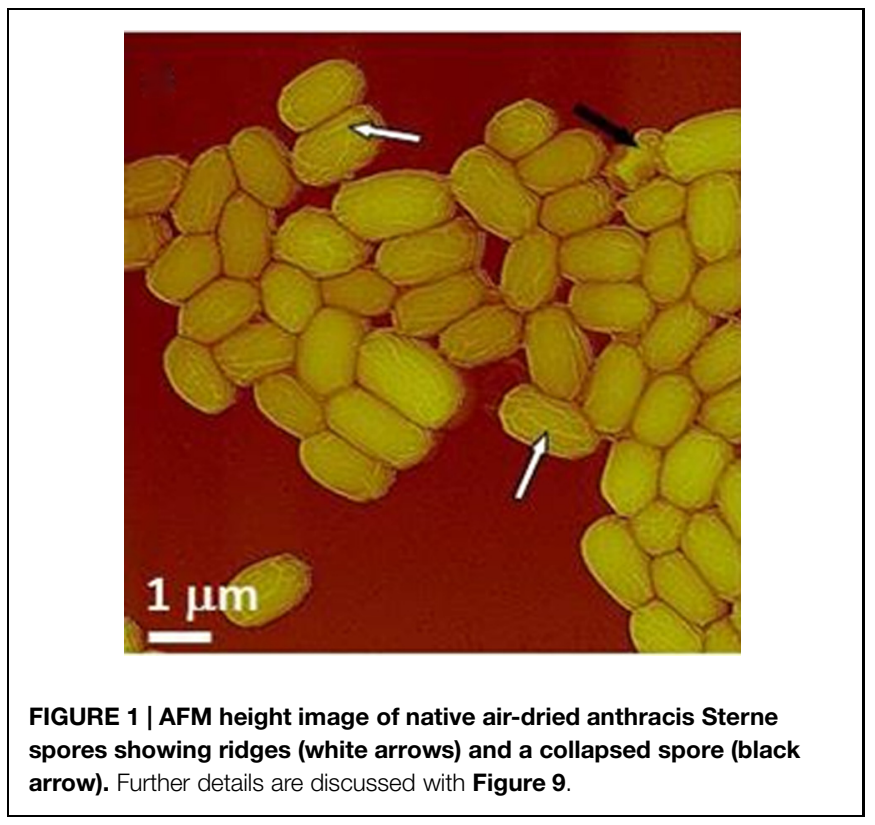

c. http://www.nbcnews.com/watch/nbc-news-channel/ researchers-develop-ebola-disinfectant-348828227663

d. http://www.army.mil/article/136641/Natick_plays_key_role_ in_helping_to_fight_spread_of_Ebola/

e. http://www.bizjournals.com/boston/blog/techflash/2015/04/ why-a-u-s-army-research-facility-in-natick-is.html

\section{Materials and Methods}

\subsection{Novel Redox Chemistry for the Production of $\mathrm{ClO}_{2}$}

Natick Soldier RD\&E Center's bacterial spore decontamination technologies comprise a number of different dry chemical oxidation-reduction systems that mix with water in a glass beaker or plastic vessel to produce chlorine dioxide $\left(\mathrm{ClO}_{2}\right)$ inside a carryable plastic suitcase, a rigid or a flexible plastic, handtriggered spray-bottle, a sealable Mylar bag, or inside closable flexible or rigid plastic packaging (such as the plastic clamshell packaging used commercially to store and distribute fresh berries and other fresh or fresh-cut produce).

The NCC (Table 1) is the primary source of generating $\mathrm{ClO}_{2}$ and involves the oxidation-reduction reaction of chlorite (Sodium chlorite, Sigma-Aldrich Cat. No. 244155) and sulfite (Sodium sulfite, Sigma-Aldrich Cat. No. 239312) through the use of a unique chemical effector (Sodium ascorbate, SigmaAldrich A7631 - see Curtin et al., 2004) that initiates and controls the rate of the otherwise kinetically inert reaction, such that the production of $\mathrm{ClO}_{2}$ takes place at near-neutral $\mathrm{pH}$ on a practical and relatively short timescale (Curtin et al., 2014). The NCC improves the generation of $\mathrm{ClO}_{2}$ compared to existing methods, which include (i) the reduction of chlorate $\left[\mathrm{ClO}_{3}{ }^{-}\right.$, $\mathrm{Cl}(\mathrm{V})]$ in high acid $\left(\mathrm{HCl}\right.$ or $\left.\mathrm{H}_{2} \mathrm{SO}_{4}\right)$; (ii) the oxidation of chlorite $\left[\mathrm{ClO}_{2}{ }^{-}, \mathrm{Cl}(\mathrm{III})\right]$ by dichlorine $\left[\mathrm{Cl}_{2}, \mathrm{Cl}(0)\right]$, hypochlorite $\left[\mathrm{OCl}^{-}\right.$, $\mathrm{Cl}(\mathrm{I})]$, or persulfate $\left[\mathrm{S}_{2} \mathrm{O}_{8}{ }^{2-}, \mathrm{S}(\mathrm{VII})\right]$, or (iii) the acidification of 
chlorite for the formation and subsequent disproportionation of chlorous acid $\left[\mathrm{HClO}_{2}, \mathrm{Cl}(\mathrm{III})\right.$; Horváth et al., 2003]. While the PCS uses the NCC system to generate gaseous $\mathrm{ClO}_{2}$, D-FENS uses the NCC in conjunction with a novel two-step mixing process (i.e., pre-concentration followed by ii. post-reaction dilution), to generate aqueous $\mathrm{ClO}_{2}$ inside a rigid or collapsible plastic spray-bottle. The chemical systems for D-FEND ALL and CoD eliminate the need for the effector and involve only two chemical components and one-step mixing for greater user convenience, but neither has been formally disclosed yet through patent procedures.

\subsection{NSRDEC's Novel Decontamination Technologies}

As reported previously (Doona et al., 2014) the novel decontamination technologies (NCC, PCS, D-FENS, D-FEND ALL, FDKs, CoD) were validated using laboratory chemical reagents and suitable challenge organisms and substrates to confirm sterility and material compatibility.

\subsubsection{The PCS}

The PCS (Figure 2) is a Modern Field Autoclave, a revolutionary medical device invented to meet a stated Army need and an urgent battlefield demand for a field-portable, non-steam sterilizer technology that can be used by far-forward surgical teams (Doona et al., 2014). The PCS produces gaseous $\mathrm{ClO}_{2}$ and proceeds where no commercial device existed previously, with a $100 \%$ reduction in power usage, $98 \%$ reduction in water, 95\% reduction in weight, and $96 \%$ reduction in cubic footprint compared to conventional steam autoclaves. The PCS used the NCC to sterilize live cultures of Geobacillus stearothermophilus spores in aqueous suspensions (recovered on Antibiotic Assay Medium with 1\% soluble starch - see Feeherry et al., 1987; Doona et al., 2014), bio-indicators of G. stearothermophilus (BT Sure biological indicator (BI), Thermo Fisher Scientific Cat No. AY759X3) and Bacillus atrophaeus [EZ Test (EtO), SGM Biotech Inc., Cat. No. EZG/6] spores, live cultures of L. monocytogenes (recovered on Tryptic Soy AgarYeast Extract (TSAYE) incubated at $T=35^{\circ} \mathrm{C}$ for $48-96 \mathrm{~h}$ ) and E. coli (recovered on Nutrient Agar) inoculated on hard surfaces (glass or stainless steel coupons) or on fresh whole tomatoes.

\subsubsection{D-FENS}

D-FENS (Figure 3) generates aqueous chlorine dioxide in a collapsible handheld spray-bottle (Doona et al., 2014) for decontaminating surfaces (fresh produce or medical, food handling, and surfaces in showers and latrines) anywhere large numbers of deployed personnel co-exist in close proximity. The D-FENS system uses the NCC with novel two-step mixing to generate aqueous $\mathrm{ClO}_{2}$ inside a rigid or collapsible plastic spray-bottle and was validated against a cocktail of Staphylococcus aureus (S. aureus A-100, produces enterotoxin A; $S$. aureus ATCC 14458, produces enterotoxin B; and S. aureus 993, produces enterotoxin D - all strains were recovered on Baird-Parker Agar containing egg yolk tellurite and Yeast Extract). For validation testing, the $S$. aureus aqueous suspension was spread onto on agar surfaces, representative of porous materials with hard-to-reach places, such as those found in realworld decontamination applications, and challenged with $\mathrm{ClO}_{2}$ solution from D-FENS.
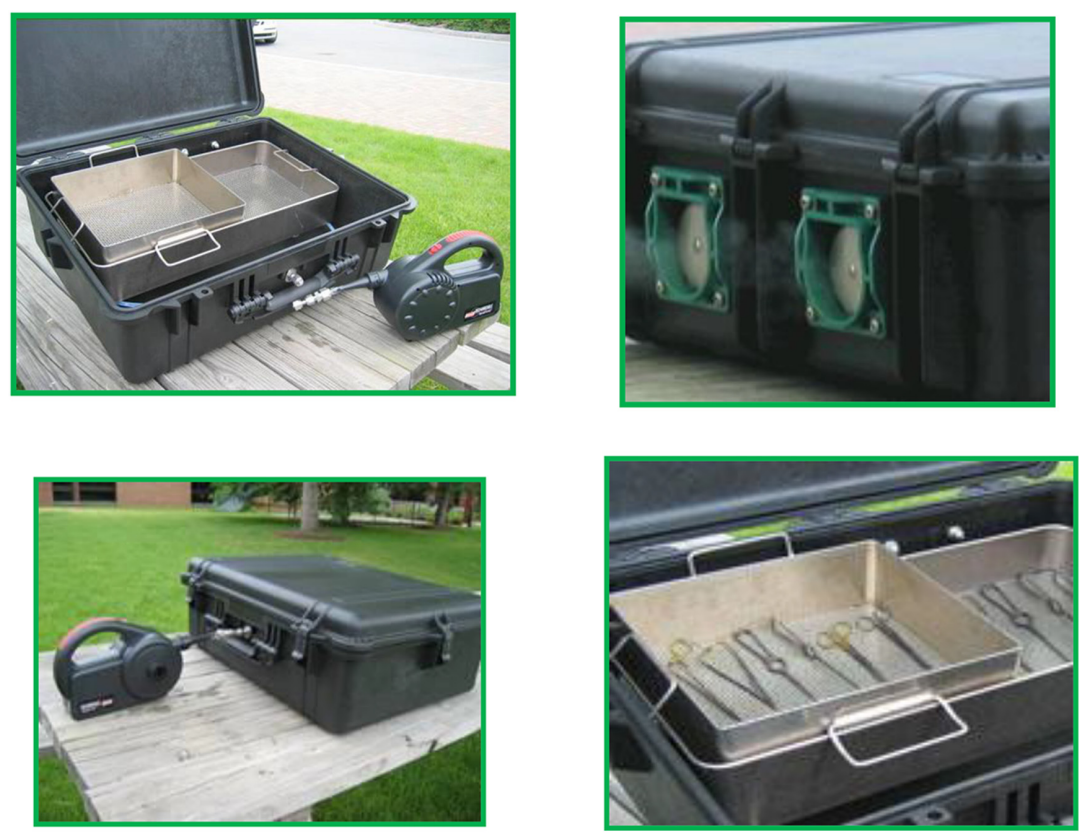

FIGURE 2 | The PCS (top left) consists of a rigid plastic suitcase embellished with reactors, valves (top right), scrubbers, and other design features (bottom left) to effectuate sterilization (bottom right) with $\mathrm{ClO}_{2}$ while protecting users and the environment. 


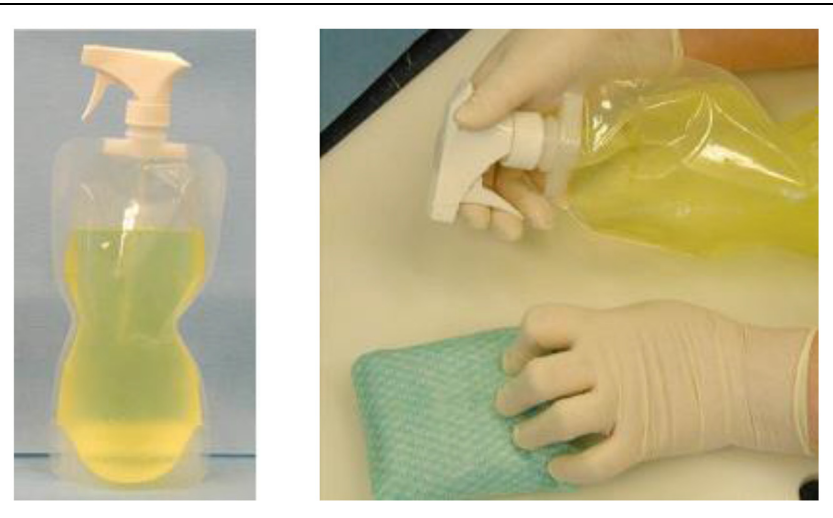

FIGURE 3 | The D-FENS sprayer generates aqueous $\mathrm{ClO}_{2}$ on-site and at point-of-use in a collapsible spray-bottle (left) and easily sprays $\mathrm{ClO}_{2}$ onto contact surfaces (right) to wipe away contaminating pathogens in Army Field Kitchens and Navy galleys.

\subsubsection{D-FEND ALL and CoD}

D-FEND ALL and CoD are chemical systems that eliminate the need for an effector in generating $\mathrm{ClO}_{2}$ with twocomponents and one-step mixing, to provide more convenience in treating water, decontaminating textiles, or for in-package anti-microbial treatments of sterile instruments or fresh fruits and vegetables. The D-FEND ALL and CoD systems use separate oxidation-reduction chemical systems that eliminate the need for the added chemical effector. D-FEND ALL (Doona et al., 2014) was validated experimentally in the laboratory to decontaminate live cultures of $B$. anthracis Delta Sterne (recovered on Nutrient Agar and incubated for 16-20 h at $T=35^{\circ} \mathrm{C}$ ) and Bacillus amyloliquefaciens spores (recovered on ST-1 Nutrient Agar incubated for $18 \mathrm{~h}$ at $T=30^{\circ} \mathrm{C}$ ) on military textiles, and compared with commercial household bleach (5-6\% aqueous hypochlorite, $\mathrm{OCl}^{-}$) and high pressure processing (HPP) for textiles immersed in water using a PT1 high pressure unit (Avure Technologies, Inc., Kent, WA, USA) with conditions of pressure $P=550 \mathrm{MPa}$, temperature $T=65^{\circ} \mathrm{C}$, and time $t=100 \mathrm{~min}$. $\mathrm{CoD}$ was validated for decontamination in rigid plastic packaging using the $G$. stearothermophilus and B. atrophaeus spore bio-indicators mentioned above.

\subsubsection{FDKs}

Field Decontamination Kits (FDKs) are based on adapting commercial versions of the NSRDEC decontamination technologies for use by global public health organizations (MSF, WHO, NIH, etc.) to sterilize Ebola-contaminated medical equipment at remote clinical sites in West Africa. First, the NCC is sold commercially as CHEMCD (ClorDiSys Solutions, Inc., Lebanon, NJ, USA) as a result of Technology Transfer licensing agreements with private industry. CHEM-CD controllably produces gaseous $\mathrm{ClO}_{2}$ to decontaminate HEPA housings, biosafety cabinets (BSCs) and hoods, and bio-aerosol chambers. CHEM-CD consists of oxidant (Part A), reductant (Part B), and neutralizer (Part C) in separate foil pouches and wrapped in plastic bag to extend shelf-life to $\sim 30$ months. A video demonstration of CHEM-CD in action is available at http://www.youtube.com/watch?v=EAh_Vz3TNTo. The benefits of using this product relate to the approval of $\mathrm{ClO}_{2}$ as a sterilant by the National Sanitation Foundation (NSF/ANSI 49 Annex G 2009) for advantages in safety, speed, and environmental-friendliness compared to conventional formaldehyde. The CHEM-CD product is the method for producing $\mathrm{ClO}_{2}$ in the deployed FDKs (Figure 4). A more detailed description of the materials and operation of the FDKs are discussed in detail in Section 3. Validation of the PCS using the CHEM-CD formulation from the FDK to sterilize G. stearothermophilus and $B$. atrophaeus bio-indicators, as reported previously (Doona et al., 2014), are presented in Section 3.1 below.

\subsection{Atomic Force Microscopy (AFM)}

Detailed experimental procedures for AFM imaging of spores were described previously (Plomp et al., 2005a,b, 2014) and are summarized here. Droplets $(\sim 2.0 \mu \mathrm{l})$ of spore suspensions were deposited on plastic cover slips and incubated for $10 \mathrm{~min}$ at room temperature, then the sample substrate was carefully rinsed with double-distilled water and allowed to dry. Images were collected using a Nanoscope IV Atomic Force Microscope (Bruker Corporation, Santa Barbara, CA, USA) operated in tapping mode. For rapid, low-resolution analysis of spore samples, fast scanning AFM probes (DMASP Micro-Actuated, Bruker Corporation, Santa Barbara, CA, USA) with resonance frequencies of $\sim 210 \mathrm{kHz}$ were utilized. For high-resolution imaging, SuperSharpSilicon (SSS) AFM probes (NanoWorld Inc., Neuchâtel, Switzerland) with tip radii $<2 \mathrm{~nm}$ and resonance frequencies of $\sim 300 \mathrm{kHz}$ were used. Nanoscope software $5.30 \mathrm{r} 3 \mathrm{sr} 3$ was used for data acquisition and subsequent processing of AFM images. In order to assess low-resolution and high-resolution spore features, raw AFM images typically needed to be modified. In particular, the contrast enhancement command, which runs a statistical differencing filter on the acquired image, was typically utilized to bring all of the features of an image to the same height and to equalize the contrast among them. This allows all features of an image to be seen simultaneously, and thus a single spore or a group of spores can be imaged at relatively low resolution while spore coat attributes can be visualized at high-resolution. Heights of spore surface features (i.e., folds, coat layers, etc.) were measured from height images using the section command. Tapping amplitude, phase, and height images were collected simultaneously. Height images allow quantitative height determinations, providing precise measurements of spore surface topography. Amplitude and phase images do not provide height information, but provide similar morphological and structural information as height images, often displaying a greater amount of structural detail and contrast compared to height images and making them a preferred choice for presentation purposes. Prior to AFM characterization, spore preparations were examined for refractility by phase-contrast light microscopy (Nikon Eclipse 50i) to determine the fraction 


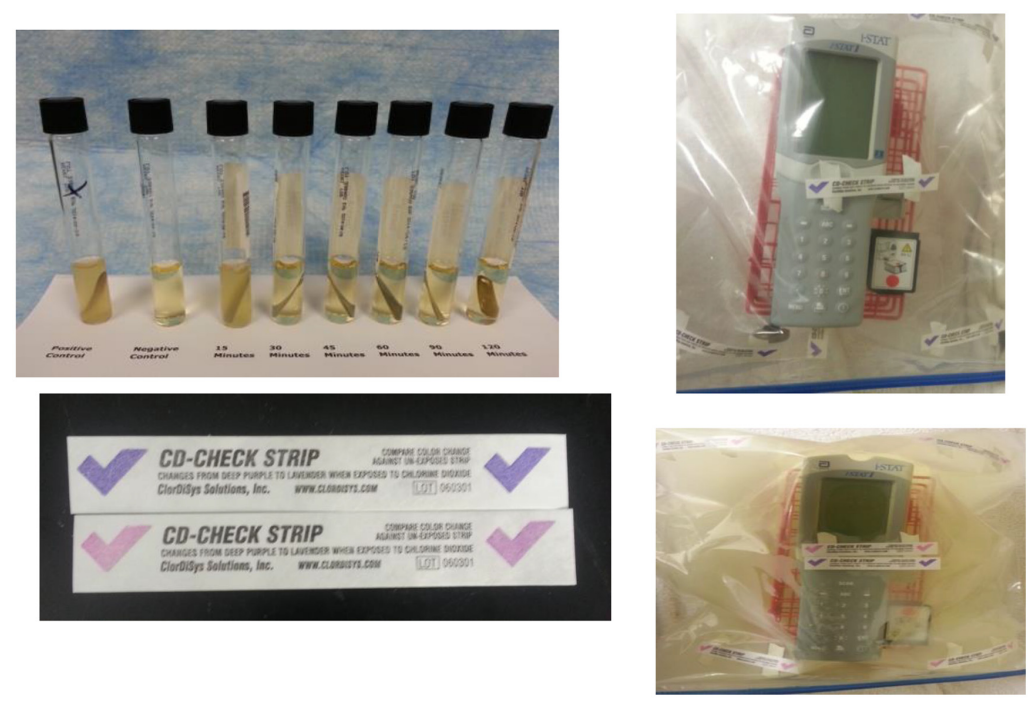

FIGURE 4 | Laboratory testing showed the FDKs were non-destructive to household electronics devices after 15 cycles (top right) and non-destructive to an iStat device after five decontamination cycles (bottom right). The FDK used a CHEM-CD configuration (see Section 3) and generated copious $\mathrm{ClO}_{2}$ gas (bottom left) and $T=80-120^{\circ} \mathrm{C}$ to kill spore indicators in $30 \mathrm{~min}$ (top left).

of ungerminated (phase bright) and germinated (phase dark) spores.

\subsection{Bacterial Spore Bio-indicators (Bl's)}

\subsubsection{Spore Strips}

Spore strips (Raven Biological Labs, Omaha, NE, USA) are inch-long pieces of cellulose paper inoculated with a known concentration of bacterial spores, and packaged in a barrier material that permits the diffusion of sterilant gas or humidified air, but excludes contaminants such as vegetative bacterial cells or other spores. Spore strips act as bio-indicators (BI's) for various sterilization/decontamination processes (ethylene oxide, abbreviated $\mathrm{EtO}, \mathrm{ClO}_{2}$, autoclaving, irradiation, etc.). Three Bacillus spore species were assayed for susceptibility to $\mathrm{ClO}_{2}: B$. atrophaeus (ATCC 9372, formerly $B$. subtilis var. niger and B. globigii), B. thuringiensis (ATCC 29730), and G. stearothermophilus (ATCC 7953, formerly Bacillus stearothermophilus). Spore strip populations for all species were determined by the manufacturer, as were $\mathrm{D}$ and $\mathrm{Z}$ (the slope of a thermal resistance curve) values for two of the three species. $\mathrm{D}$ values for ethylene oxide $\left(\mathrm{D}_{\mathrm{EtO}}\right)$ and dry heat $\left(\mathrm{D}_{160}\right)$ were determined for B. atrophaeus, while D values for saturated steam $\left(\mathrm{D}_{121}\right.$ and $\left.\mathrm{D}_{132.2}\right)$ were determined for G. stearothermophilus. No such values were determined for B. thuringiensis. Species lot numbers, populations, and relevant $\mathrm{D}$ and $\mathrm{Z}$ values are listed in Table 2.

\subsubsection{BI Packaging Material}

The BI packaging material contributes a crucial factor in the efficacy of the $\mathrm{ClO}_{2}$ sterilizing process. In this report, we investigate BI's packaged either in 1059B medical grade Tyvek (single-sided with a plastic backing; Raven Industries, Sioux Falls, $\mathrm{SD}$, USA) or nothing, as our preliminary data suggested that
1059B was relatively non-reactive and non-attenuating for $\mathrm{ClO}_{2}$. To comply with current industry standards, we also show that $\mathrm{ClO}_{2}$ is an efficacious sterilant of $B$. atrophaeus BI's packaged in medical grade glassine (Raven Industries, Sioux Falls, SD, USA).

\subsection{3. $\mathrm{ClO}_{2}$ Generation and Treatment}

Chlorine dioxide was generated by the oxidation of technical grade sodium chlorite $\left(\mathrm{NaClO}_{2}\right)$ by sodium persulfate $\left(\mathrm{Na}_{2} \mathrm{~S}_{2} \mathrm{O}_{8}\right.$; Sigma-Aldrich Co., St. Louis, MO, USA) in aqueous solution:

$$
2 \mathrm{NaClO}_{2}+\mathrm{Na}_{2} \mathrm{~S}_{2} \mathrm{O}_{8} \rightarrow 2 \mathrm{ClO}_{2}+2 \mathrm{Na}_{2} \mathrm{SO}_{4}
$$

Pure gaseous $\mathrm{ClO}_{2}$, free of volatile by-products such as $\mathrm{Cl}_{2}$, was purged from the reaction flask and diluted with ratios of filtered, dehumidified and humidified air to attain the target $\mathrm{ClO}_{2}(\mathrm{~g})$ concentration and $\mathrm{RH}$ conditions. $\mathrm{RH}$ was controlled with a series of flow meters (Cole Parmer, Vernon Hills, IL, USA) passing filtered and dehumidified air through a $500 \mathrm{~mL}$ gas wash bottle half filled with deionized water. The humidified diluted gas was directed into a $5 \mathrm{~L}$ glass test chamber (Thermo Fisher Scientific, Waltham, $\mathrm{MA}$, USA), and $\mathrm{ClO}_{2}$ concentration $\left(\left[\mathrm{ClO}_{2}\right]\right)$ in parts per million (ppm) was determined by iodometric titration of a 50 or $100 \mathrm{~mL}$ volume/sample of gas taken/removed/sampled from the exit port of the reaction chamber in a gastight Hamilton sample-lock syringe (Fisher). Experiments were carried out at ambient temperature and atmospheric pressure (measured and monitored with a Traceable ${ }^{\circledR}$ Digital Hygrometer/Thermometer (VWR International, Radnor, PA, USA), with $\mathrm{RH}$ ranging from 30 to $90 \%$, and $\left[\mathrm{ClO}_{2}\right]$ ranging from approximately 50 to $2000 \mathrm{ppm}$. Experimentally 
TABLE 2 | Spore strip bio-indicator characteristics.

\begin{tabular}{|c|c|c|c|c|c|c|}
\hline Species & ATCC\# & Lot\# & Population & $D_{160}$ value & D Eto value $_{\text {E }}$ & Z-value \\
\hline Bacillus atrophaeus & 9372 & 1162052 & $2.0 \times 10^{6}$ & 2.6 & 3.0 & 44.5 \\
\hline B. atrophaeus & 9372 & 1161841 & $1.3 \times 10^{6}$ & 2.5 & 3.3 & 23.5 \\
\hline B. atrophaeus & 9372 & 1161911 & $1.3 \times 10^{6}$ & 2.5 & 3.8 & 46.0 \\
\hline \multicolumn{7}{|l|}{ Batch 204GB: } \\
\hline B. atrophaeus & 9372 & 1142042 & $1.2 \times 10^{4}$ & 2.8 & 3.1 & 39.0 \\
\hline B. atrophaeus & 9372 & 1152041 & $1.2 \times 10^{5}$ & 2.8 & 3.1 & 39.0 \\
\hline B. atrophaeus & 9372 & 1162043 & $1.2 \times 10^{6}$ & 2.8 & 3.1 & 39.0 \\
\hline B. atrophaeus & 9372 & 1172041 & $1.2 \times 10^{7}$ & 2.8 & 3.1 & 39.0 \\
\hline \multicolumn{7}{|l|}{ Batch 214GB: } \\
\hline B. atrophaeus & 9372 & 1142141 & $3.5 \times 10^{4}$ & 2.8 & 5.0 & 33.3 \\
\hline B. atrophaeus & 9372 & 1152141 & $2.0 \times 10^{5}$ & 2.8 & 5.0 & 33.3 \\
\hline B. atrophaeus & 9372 & 1162141 & $1.5 \times 10^{6}$ & 2.8 & 5.0 & 33.3 \\
\hline B. atrophaeus & 9372 & 1172141 & $1.5 \times 10^{7}$ & 2.8 & 5.0 & 33.3 \\
\hline B. atrophaeus & 9372 & 1182141 & $1.5 \times 10^{8}$ & 2.8 & 5.0 & 33.3 \\
\hline \multirow[t]{2}{*}{ B. thuringiensis } & 29730 & 616022 & $1.2 \times 10^{6}$ & $\mathrm{n} / \mathrm{a}$ & $\mathrm{n} / \mathrm{a}$ & $\mathrm{n} / \mathrm{a}$ \\
\hline & & & & $D_{121}$ value & $D_{132.2}$ value & Z-value \\
\hline Geobacillus stearothermophilus & 7953 & 3166031 & $1.0 \times 10^{6}$ & 2.0 & 0.07 & 7.5 \\
\hline
\end{tabular}

TABLE 3 | Experimental $\mathrm{ClO}_{2}$ target and actual concentrations.

\begin{tabular}{|c|c|c|c|c|c|c|c|c|}
\hline \multicolumn{3}{|c|}{$\mathrm{ClO}_{2}$ concentration (ppm) } & \multicolumn{3}{|c|}{$\mathrm{ClO}_{2}$ dose } & \multicolumn{3}{|c|}{$\%$ RH } \\
\hline Target & Measurement & SD & Target & Measurement & SD & Target & Measurement & SD \\
\hline 50 & 50 & 4 & 400 & 414 & 20 & 30 & 30.32 & 0.006 \\
\hline 67 & 68 & 4 & 1000 & 1037 & 32 & 40 & 38.75 & 0.011 \\
\hline 100 & 110 & 17 & 2000 & 2020 & 40 & 50 & 49.51 & 0.015 \\
\hline 125 & 131 & 6 & 4000 & 4046 & 88 & 60 & 59.41 & 0.013 \\
\hline 167 & 177 & 21 & & & & 70 & 69.36 & 0.011 \\
\hline 200 & 218 & 14 & & & & 80 & 79.42 & 0.015 \\
\hline 250 & 256 & 23 & & & & 90 & 89.67 & 0.01 \\
\hline 400 & 405 & 31 & & & & & & \\
\hline 500 & 498 & 40 & & & & & & \\
\hline 800 & 784 & 53 & & & & & & \\
\hline 1000 & 1027 & 115 & & & & & & \\
\hline 2000 & 2027 & 303 & & & & & & \\
\hline
\end{tabular}

Room temperature $=21.5^{\circ} \mathrm{C}, S D=0.770$.

TABLE 4 | Tyvek spore strip data summary.

\begin{tabular}{|c|c|c|c|c|c|c|}
\hline \multirow[t]{2}{*}{ Species } & \multicolumn{2}{|c|}{ Runs } & \multirow[t]{2}{*}{$N$} & \multirow{2}{*}{$\begin{array}{l}\text { Dose } \\
\left(p p m \mathrm{ClO}_{2} \times t\right)\end{array}$} & \multirow[t]{2}{*}{$\%$ RH } & \multirow[t]{2}{*}{$\mathbf{D}_{\text {EtO }}$} \\
\hline & Tyvek & No pkg & & & & \\
\hline Bacillus atrophaeus & 152 & 144 & $1.2 \times 10^{4}-1.0 \times 10^{6}$ & $110-1991$ & 79 & 3.1 \\
\hline B. atrophaeus & 490 & 350 & $3.5 \times 10^{4}-1.5 \times 10^{8}$ & $110-1991$ & 79 & 5.0 \\
\hline B. atrophaeus & 500 & 500 & $1.3 \times 10^{6}$ & $438-4106$ & 30-90 & 3.3 \\
\hline B. atrophaeus & 498 & 495 & $1.3 \times 10^{6}$ & $438-4106$ & $30-90$ & 3.8 \\
\hline B. thuringiensis & 98 & 98 & $1.2 \times 10^{6}$ & $438-4106$ & 79 & - \\
\hline G. stearothermophilus & 80 & 80 & $1.0 \times 10^{6}$ & $438-4106$ & 79 & - \\
\hline
\end{tabular}

measured values for temperature, $\mathrm{RH}$ and $\left[\mathrm{ClO}_{2}\right]$ are listed in Table 3.

To ensure exposure and contact of BIs with $\mathrm{ClO}_{2}$, no more than 20 spore strips were placed in the test chamber at one time, and, thus, multiple runs at each reported dose were performed in order to (i) assure repeatability of our results, and (ii) gather enough data to achieve statistically significant results (Table 4). One negative control strip (no inoculum and packaged 
appropriately) was included in the chamber for each set of 10 test strips, and a positive control strip remained outside of the test chamber and away from other potential sterilizing agents for the duration of each experiment.

\subsubsection{Microbiological Assays of Sterility}

After exposure to the appropriate $\mathrm{ClO}_{2}$ dose, the strips were placed, using aseptic technique, into tubes of Tryptic Soy Broth containing a Bromocresol Purple $\mathrm{pH}$ indicator (Raven Industries, Sioux Falls, SD, USA) and incubated at $37^{\circ} \mathrm{C}$ (B. atrophaeus and $B$. thuringiensis) or $60^{\circ} \mathrm{C}$ (G. stearothermophilus) for 7 days. We monitored the tubes on a daily basis for both turbidity (indicative of bacterial growth) and color change of the $\mathrm{pH}$ indicator from purple to yellow (indicative of metabolism). Criteria for a strip being considered "killed" were findings of both no turbidity and of no color change of the $\mathrm{pH}$ indicator, coupled with growth and metabolism for the positive control associated with the sample test set and no growth for the negative control.

\subsubsection{Statistical Analysis and Modeling}

We fitted a binomial generalized linear model with a complementary log-log link function to the proportion of strips still having live spores after treatment, allowing the dispersion parameter to be greater than one to account for over-dispersion. We adjusted for covariates such as (logarithm of) the number of spores on a strip, the type of packaging used to store the spore strips, $\mathrm{RH}$, and $\mathrm{D}_{\mathrm{EtO}}$ values. The model in its most general form is expressed as Eq. (1)

$$
\begin{aligned}
\log (-\log (1-\varnothing))= & b_{0}+b_{1} * \text { Dose }+b_{2} * \log N+ \\
& b_{3} * \text { Pack }+b_{4} * R H \\
& +b_{5} * D_{E t O}
\end{aligned}
$$

in which $\varnothing$ is the probability of a strip still having living spores after treatment, $p_{N}$ is the probability of a spore remaining alive after treatment (depends on $N$ ), Dose is the dose of $\mathrm{ClO}_{2}$ as calculated by $\mathrm{ClO}_{2}$ ppm multiplied by exposure time (in units of hours), $N$ is the number of spores on a strip, Pack equals 1 , if spore strips came in Tyvek packaging, and Pack equals 0 , if there were no packaging, $R H$ is the relative humidity $(\mathrm{RH}$; as a proportion), $D_{E t O}$ is the time (in units of minutes) to reduce the number of living spores to $10 \%$ of the original value by ethylene oxide (Table 5), and b's are regression coefficients. The relationship between the strip survival probability $\varnothing$ and the spore survival probability $p_{N}$ is expressed in Eq. (2)

$$
1-\varnothing=\left(1-p_{N}\right)^{N}
$$

and Eq. (1) can be re-written as Eq. (3)

$$
\begin{aligned}
\log \left(-\log \left(1-p_{N}\right)\right)= & b_{0}+b_{1} * \text { Dose }+\left(b_{2}-1\right) * \log N+ \\
& b_{3} * \text { Pack }+b_{4} * R H+b_{5} * D_{E t O}
\end{aligned}
$$

The range of values of each of the covariates in the various experiments is described in (Table 4). Although the independent variable is the strip survival probability $\varnothing$, Figures 5-7 are reported in terms of our primary measure of interest, which is the probability $p_{N}$ that any single spore survives.

\section{Results - Field Decontamination Kits in the Ebola crisis}

Emerging and re-emerging viral infectious diseases have been identified as a major threat to human health, and the current outbreak of EVD has impacted a large part of Western Africa. Conventional procedures for the decontamination of equipment during a filovirus outbreak rely on the use of chemical chlorine (bleach, aqueous hypochlorite, $\mathrm{OCl}^{-}$) for decontamination when exiting an isolation/treatment center. Electrical equipment that enters an isolation/treatment center and diagnostic facilities can only be surface decontaminated by aqueous rinses with $0.5-5.0 \%$ chlorine bleach solution (household bleach is about $6 \% \mathrm{OCl}^{-}$). This procedure is likely not adequate for complete decontamination of the devices, particularly for accessing inside the devices.

Devices such as personal cell phones, computers, and most importantly, expensive medical point-of-care (POC) electronic devices used for clinical assessment of patients in isolation/treatment ward are not sufficiently decontaminated by surface rinses. Some medical diagnostic devices have closed systems internal to the device that may have infrequent but probable contamination that cannot be adequately decontaminated by surface rinses with a chemical decontaminating agent. Often these devices contain valuable internal components that may be recycled after being surface decontaminated. This is extremely problematic for items used in a high hazard environment. For low resource, remote sites, the deployment of traditional decontamination tools is nearly impossible. Often there is limited space for equipment, so another desirable aspect of the FDK method is its compact size and simple disposal routine post-decontamination cycle.

Given the wide use of and acceptability of chlorine bleach solutions in laboratories and in isolation/treatment centers, and the historical use of chlorine dioxide in the decontamination of equipment in the U.S., we decided to adapt a chlorine dioxide method to provide equipment decontamination for deployment in the field in areas of active outbreak. This safe and adaptable method uses a commercially available chemical combination kit called CHEM-CD (ClorDiSys Solutions, Inc., Lebanon, NJ, USA) in which the components are packaged separately and isolated from water to prevent chemical reaction from taking place (Figure 8A). Once mixed together with water, the chemical reduction of sodium chlorite initiates within minutes, and a well-controlled, exothermic reaction takes place that releases chlorine dioxide gas from solution. This reaction is carefully designed to occur inside a closable plastic bag, such that the $\mathrm{ClO}_{2}$ released decontaminates thoroughly the entire interior volume of the bag and all items contained therein, including permeating the interior regions of the electronic medical and other devices inside the decontamination bag. Humidity $(\geq 70 \%$ $\mathrm{RH}$ ) and mild heat and mild pressure accumulate inside the bag from the chemical reaction occurring inside a closed 


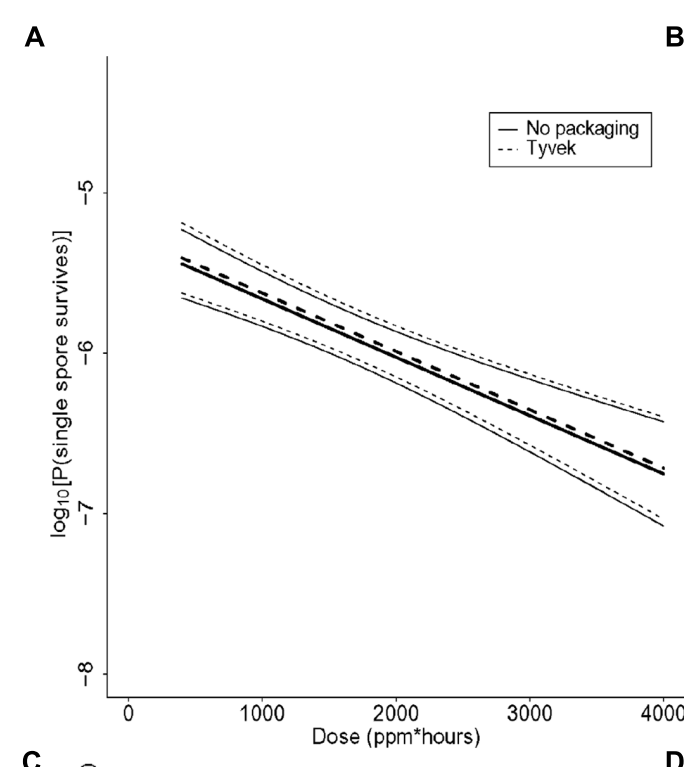

B

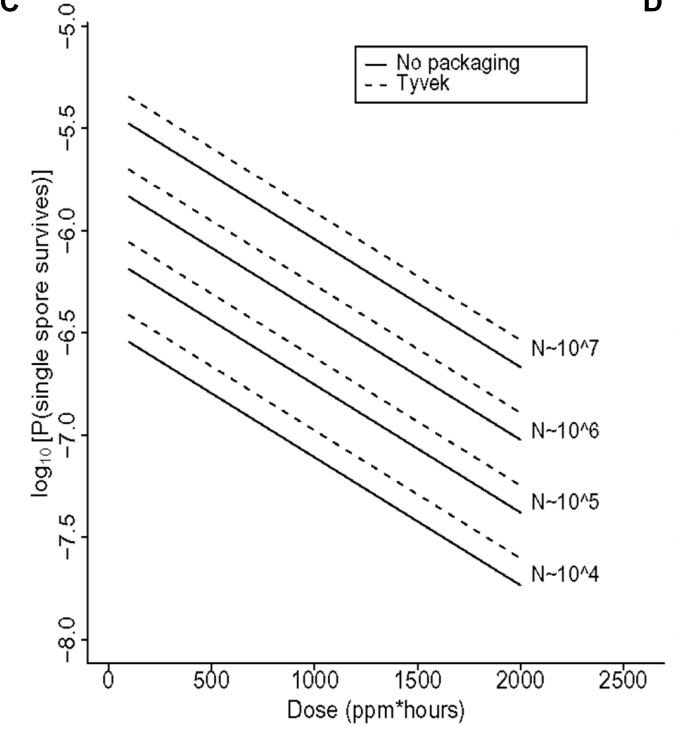

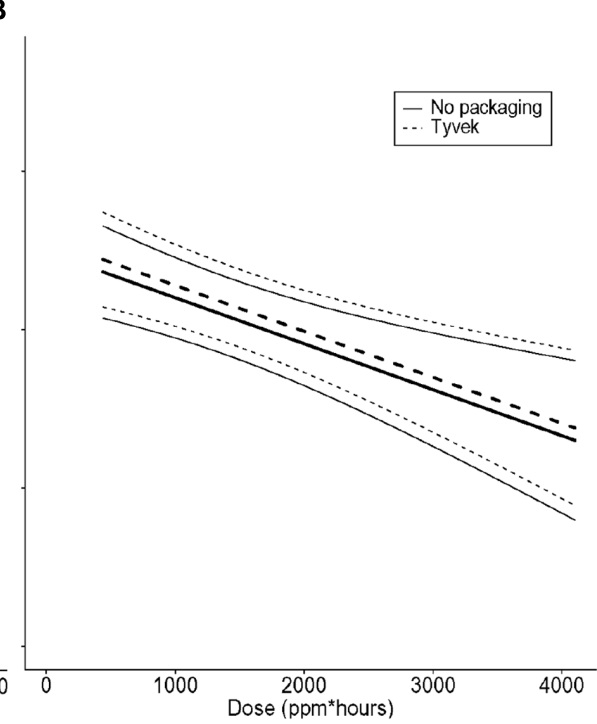

D

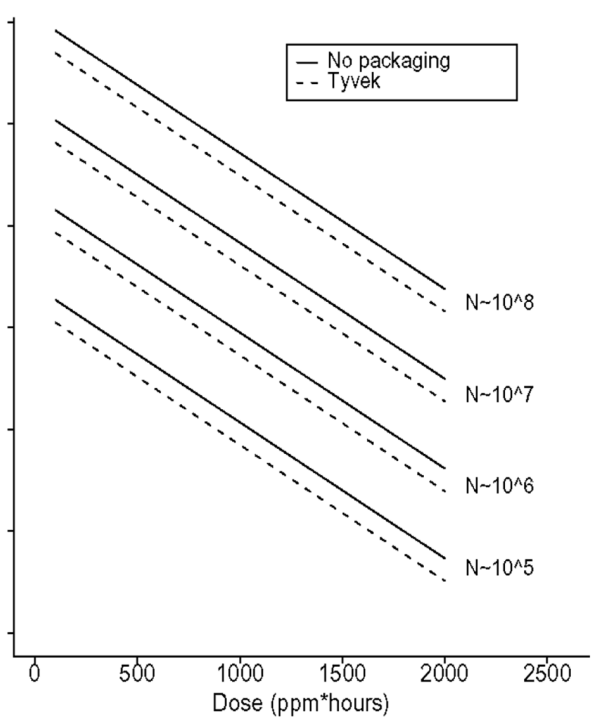

FIGURE 5 | (A) Statistical modeling showing the probability, with 95\% confidence, of a single $B$. thuringiensis spore surviving a $\mathrm{ClO}_{2}$ dose range of 438-4106 ppm-h at 79\% RH. The spore population of each strip is fixed at $1.2 \times 10^{6}$, and $n=98$ each for strips contained in Tyvek or with no packaging In the figure, the lighter set of dashed and solid lines represent the confidence interval for spore strips packaged in Tyvek or no packaging, respectively, while the middle bold lines represent the predicted probabilities. In this model, there is strong evidence of an effect of dose $(p=0.002)$ and no evidence of an effect of packaging $(p=0.76)$. (B) Statistical modeling showing the probability, with $95 \%$ confidence, of a single $\mathrm{G}$. stearothermophilus spore surviving a $\mathrm{ClO}_{2}$ dose range of $438-4106 \mathrm{ppm}-\mathrm{h}$ at $79 \% \mathrm{RH}$. The spore population of each strip is fixed at $1.0 \times 10^{6}$, and $n=80$ each for strips contained in Tyvek or no packaging. Lighter dashed and solid lines represent the confidence interval for spore strips packaged in Tyvek or no packaging, respectively, while the middle bold lines represent the predicted probabilities. There is evidence of an effect of dose $(p=0.02)$ and no evidence of an effect of packaging $(p=0.68)$.
(C) Predicted probabilities of a single spore surviving for varying numbers of B. atrophaeus spores $\left(1.2 \times 10^{4}\right.$ to $\left.1.2 \times 10^{7}\right)$, with a $D_{\text {EtO }}$ value of 3.1 , in Tyvek $(n=152)$ and no packaging $(n=144)$ at $79 \% \mathrm{RH}$ and $\mathrm{ClO}_{2}$ dose ranging from 110 to $1991 \mathrm{ppm}-\mathrm{h}$. There is strong evidence that increased dose decreases the probability of any strips having live spores $(p<0.01)$ and that as the number of spores on the strip increases, so does the probability of survival $(p<0.01)$. There is no evidence of a significant effect of packaging on survival of spores $(p=0.21)$, though there is some difference with a slightly higher rate of survival for spores packaged in Tyvek. (D) Predicted probabilities of a single spore surviving for varying numbers of $B$. atrophaeus spores $\left(3.5 \times 10^{4}\right.$ to $\left.1.5 \times 10^{8}\right)$, with a $D_{\text {EtO }}$ value of 5.0 , in Tyvek $(n=490)$ and no packaging $(n=350)$ at $79 \% \mathrm{RH}$ and $\mathrm{ClO}_{2}$ dose ranging from 110 to $1991 \mathrm{ppm}-\mathrm{h}$. These results indicate that the probability of a strip having live spores after treatment increases with decreasing dose $(p<0.01)$ and with increasing numbers of spores $(p<0.01)$. There is no evidence of an effect of packaging $(p=0.21)$, although there is a slightly lower rate of survival for spores in Tyvek packagi. container, but the heat and pressure gently subside over the 3060 min decontamination period. Human exposure to $\mathrm{ClO}_{2}$ above permissible concentrations and durations is known to cause irritation of the eyes, skin, nose, throat and lungs, and thus this method is typically used in outdoor environments with exposure to the sun. 


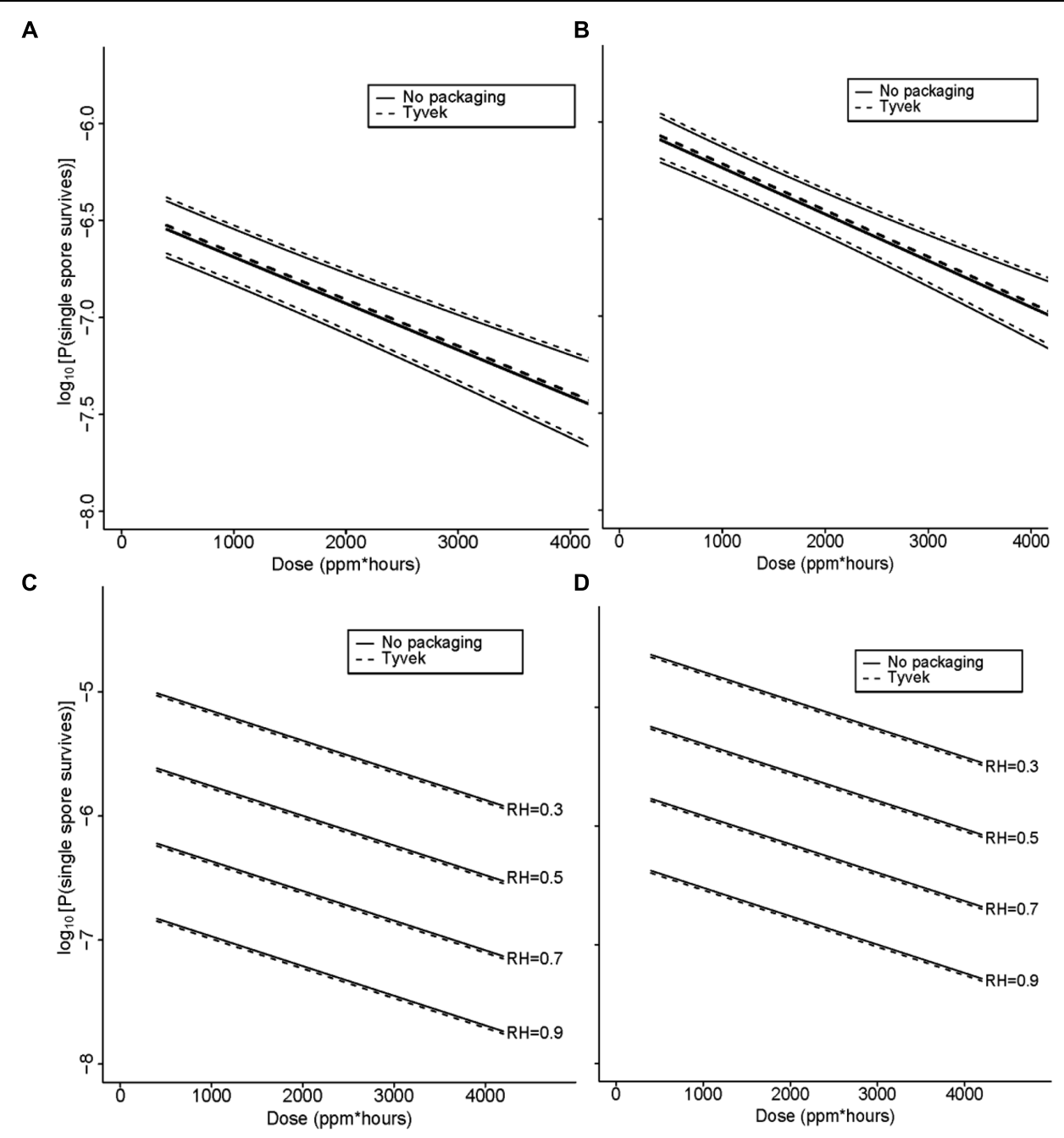

FIGURE 6 | (A) Statistical modeling showing the probability, with 95\% confidence, of a single $B$. atrophaeus spore, with a $D_{\text {Eto }}$ value of 3.1 and fixed strip inoculum of $10^{6}$, in Tyvek $(n=38)$ and no packaging $(n=36)$, surviving a $\mathrm{ClO}_{2}$ dose range of $110-199 \mathrm{ppm}-\mathrm{h}$ at $79 \% \mathrm{RH}$. In the figures (A-D), the lighter set of dashed and solid lines represent the confidence interval for spore strips packaged in Tyvek or no packaging, respectively, while the middle bold lines represent the predicted probabilities.

(B) Statistical modeling showing the probability, with 95\% confidence, of a single $B$. atrophaeus spore, with a $D_{\text {Eto }}$ value of 5.0 and fixed strip inoculum of $10^{6}$, in Tyvek $(n=98)$ and no packaging $(n=70)$, surviving a $\mathrm{ClO}_{2}$ dose range of $110-1991 \mathrm{ppm}-\mathrm{h}$ at $79 \% \mathrm{RH}$. (C) Predicted probabilities for a single $B$. atrophaeus spore, with a $D_{\text {EtO }}$ value of 3.3 and fixed strip inoculum of $1.3 \times 10^{6}$, in Tyvek ( $n=500$, dashed line) or no packaging ( $n=500$, solid line). (D) A $D_{\text {Eto }}$ value of 3.8 and fixed strip inoculum of $1.3 \times 10^{6}$, in Tyvek ( $n=498$, dashed line) or no packaging ( $n=498$, solid line), surviving a range of $\mathrm{ClO}_{2}$ doses with $\mathrm{RH}$ varying from 30 to $90 \%$. The results of this fitted model, which has an offset term of $\log (\mathrm{N}$; fixed in this example) shows again that dose has a similarly strong effect as previously in that increasing it decreases the probability of spores surviving on a strip $(p<0.01)$. There is no evidence of an effect of packaging $(p=0.73)$, and there is strong evidence of an increase in survival probability with increasing $D_{\text {Eto }}$ values $(p<0.01)$ and with decreasing $\mathrm{RH}(p<0.01)$. The $D_{\text {Eto }}$ variable was treated as a categorical variable to be consistent with earlier models and so the regression coefficient compares $D_{E t O}=3.3$ to $D_{E t O}=3.8$.
Adapting this method for field decontamination was ideal, because it is devoid of electrical power sources, uses small quantities of water from available sources, and the low cost of the FDKs, and with the required supplies simple and easy to obtain, store, and handle for $\mathrm{ClO}_{2}$ generation. Specifically, this method was used to develop FDKs (Table 1; Figure 8B) comprising a selfsealable bag ( 2 or 10 gallon capacity), dry chemical components (Part A and Part B from the commercially available CHEM$\mathrm{CD}$ kit) that react in water to produce chlorine dioxide. The FDK also includes a device to measure water (50 $\mathrm{mL}$ tube) and
$\mathrm{ClO}_{2}$ indicators of sterility (CD Check Strip, ClorDiSys Solutions, Inc., Lebanon, NJ, USA). In addition, laboratory testing with spore BIs (G. stearothermophilus for steam sterilization from BT Sure, Thermo Scientific, Marietta, OH, USA, and B. atrophaeus for ethylene oxide sterilization from EZ Test, SGM Biotech, Inc., Bozeman, MT, USA as discussed above) showed complete inactivation of spores (sterility) was achieved within $30 \mathrm{~min}$ of exposure.

Figure 8A illustrates the procedural steps carried out in utilizing the FDKs. Briefly, the $\mathrm{ClO}_{2}$ indicators are taped to the 
A

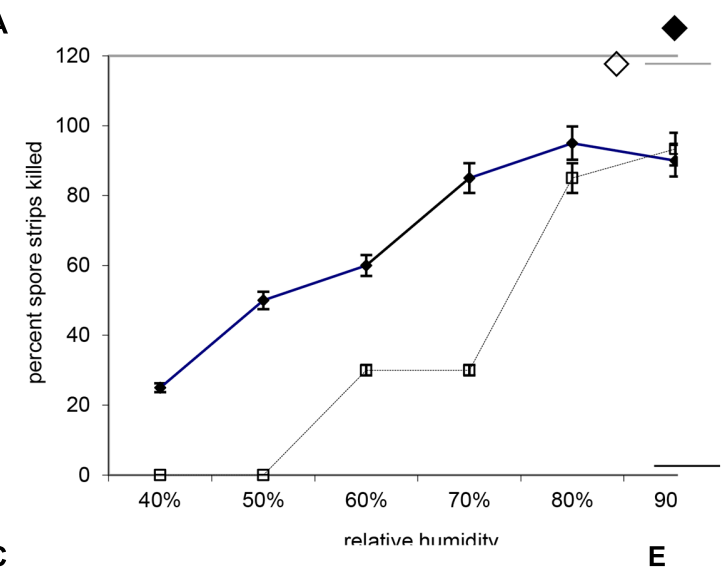

B

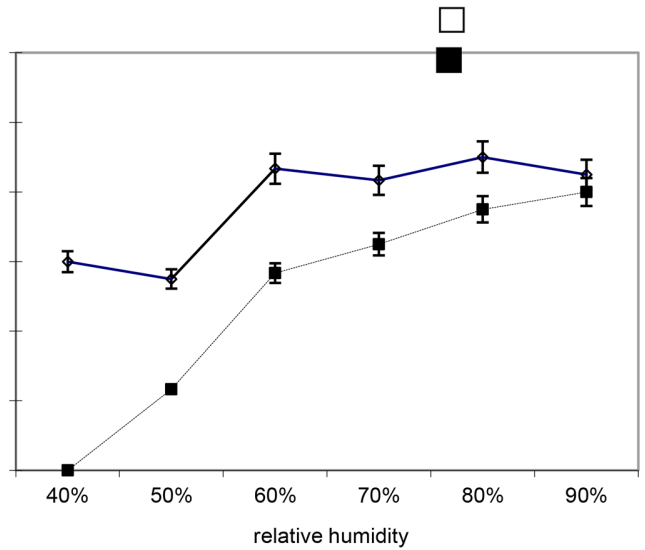

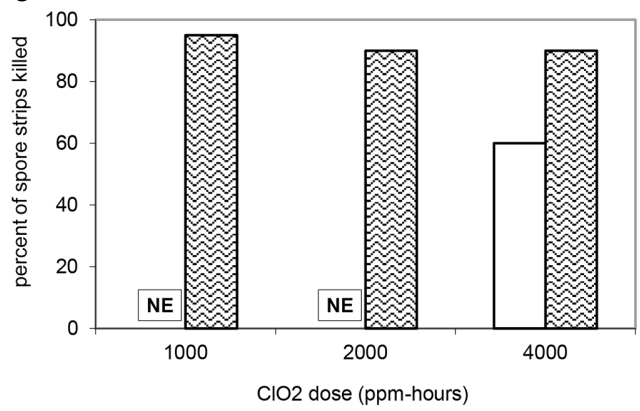

D

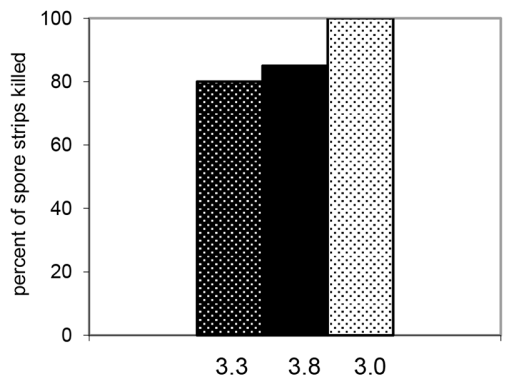

FIGURE 7 | Increasing RH at a fixed dose of (A) $500 \mathrm{ppm} \mathrm{ClO}_{2}$ for $4 \mathrm{~h}$ ( 2000 ppm-h) and (B) $1000 \mathrm{ppm} \mathrm{ClO}_{2}$ for $4 \mathrm{~h}(\sim 4000 \mathrm{ppm}-\mathrm{h})$ results in a higher percentage of $\log 6 \mathrm{~B}$. atrophaeus spore strips being killed.

(A) B. atrophaeus $\mathrm{D}_{\mathrm{EtO}}=3.3(n=120),=B$. atrophaeus $\mathrm{D}_{\mathrm{EtO}}=3.8(n=160)$; (B) B. atrophaeus $D_{E t O}=3.3(n=140)$, and $B$. atrophaeus $D_{E t O}=3.8$ $(n=140)$. Data shown is for spore strips packaged in Tyvek. For the $D_{\mathrm{EtO}}=3.3$ strips exposed to $2000 \mathrm{ppm}-\mathrm{h} \mathrm{ClO}_{2}, \geq 80 \%$ kill is achieved at $70 \% \mathrm{RH}$ and above, but when we increase the dose to $\sim 4000 \mathrm{ppm}-\mathrm{h}$ the same level of kill is achieved at \%RH of 60 . The relationship between low $\mathrm{D}_{\text {Eto }}$ value and increased susceptibility to $\mathrm{ClO}_{2}$ is evident, though, in this example, we see that at $90 \% \mathrm{RH}$ all four sample sets are behaving roughly the same. (C) $B$. atrophaeus

$D_{\text {EtO }}=3.3, \log 6$ spore strips packaged in $\square=$ medical-grade glassine, and $:=$ Tyvek are not equally susceptible to a set $\mathrm{ClO}_{2}$ dose at $79 \% \mathrm{RH}(\mathrm{NE}=$ no effect). Spore strips were exposed to $250 \mathrm{ppm} \mathrm{ClO}_{2}$ for $4 \mathrm{~h}$ (dose $\approx 1000 \mathrm{ppm}-\mathrm{h}$ ), where $n=20$ each for glassine and Tyvek; $2000 \mathrm{ppm}-\mathrm{h}$, where $n=40$ (glassine) and $n=20$ (Tyvek); and 4000 ppm-h, where $n=40$ (glassine)

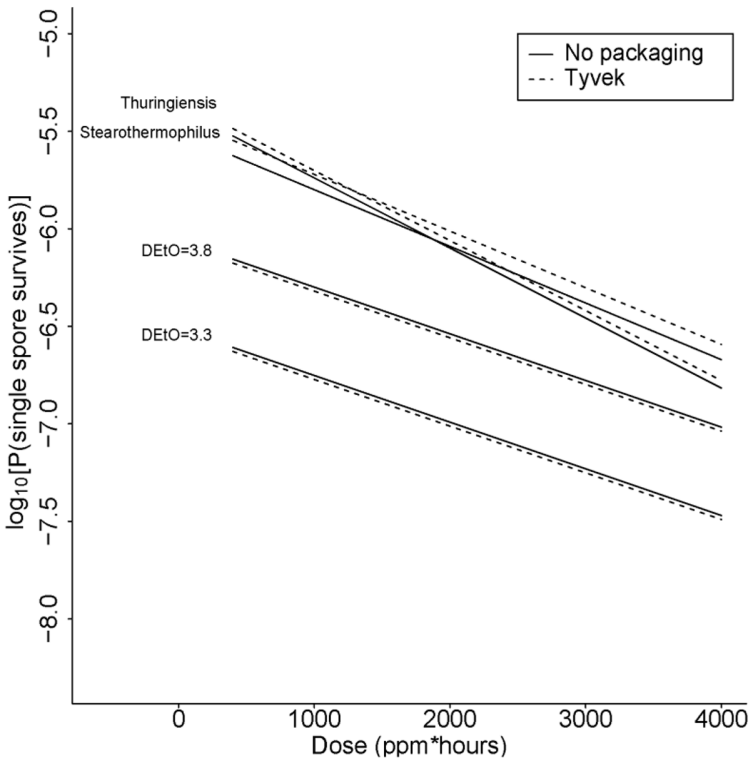

and $n=20$ (Tyvek) at constant temperature and \%RH. (D) We did not achieve $100 \%$ kill for glassine-packaged log 6 spore strips until we subjected a lot of B. atrophaeus with $\mathrm{D}_{\mathrm{EtO}}$ value of $3.0(n=20)$ to $2000 \mathrm{ppm}$ for $10 \mathrm{~h}$ ( 20,000 ppm-h) at $79 \% \mathrm{RH}$. This high dose killed 80 and $85 \%$ of B. atrophaeus $\mathrm{D}_{\mathrm{EtO}}=3.3$ and 3.8 ( $n=20$ each) spore strips, respectively. (E) For all three species and B. atrophaeus with two different $D_{\text {EtO }}$ values (3.3, with $n=80$ for each Tyvek and no packaging; and 3.8, with $n=189$ for each Tyvek and no packaging), probabilities were predicted for a spore surviving after treatment, with $\mathrm{RH}=0.79$ and $N=10^{6}$. Note that for $B$. thuringiensis ( $n=98$ each for Tyvek and no packaging), measurements were only made at $N=1.2 \times 10^{6}$. For both sets of $B$. atrophaeus, measurements were made at $N=1.3 \times 10^{6}$, so in these cases this plot involves extrapolation in $N$. $B$. thuringiensis, the closest phylogenetic relative to Bacillus anthracis used in this study, is more likely to survive at any given $\mathrm{ClO}_{2}$ dose than either of the $B$. atrophaeus strains, though it's resistance is similar to the strain of G. stearothermophilus ( $n=80$ each for Tyvek and no packaging) assayed. inner bag to be observed during the decontamination process and the chemical reagents Part $\mathrm{A}$ and Part $\mathrm{B}$ are placed in a container with water. The item to be decontaminated is placed in the bag near or over the mixture and the bag is subsequently sealed. Within a few minutes the reaction produces condensation (humidity) and yellow $\mathrm{ClO}_{2}$ gas that inflates the bag due to a mild build-up of heat and pressure, although the bag itself does not become turgid. After a minimum of $30 \mathrm{~min}$, the color change of the indicator shows adequate concentration and exposure to $\mathrm{ClO}_{2}$ gas to achieve sterility, and the bag can be opened to 
A
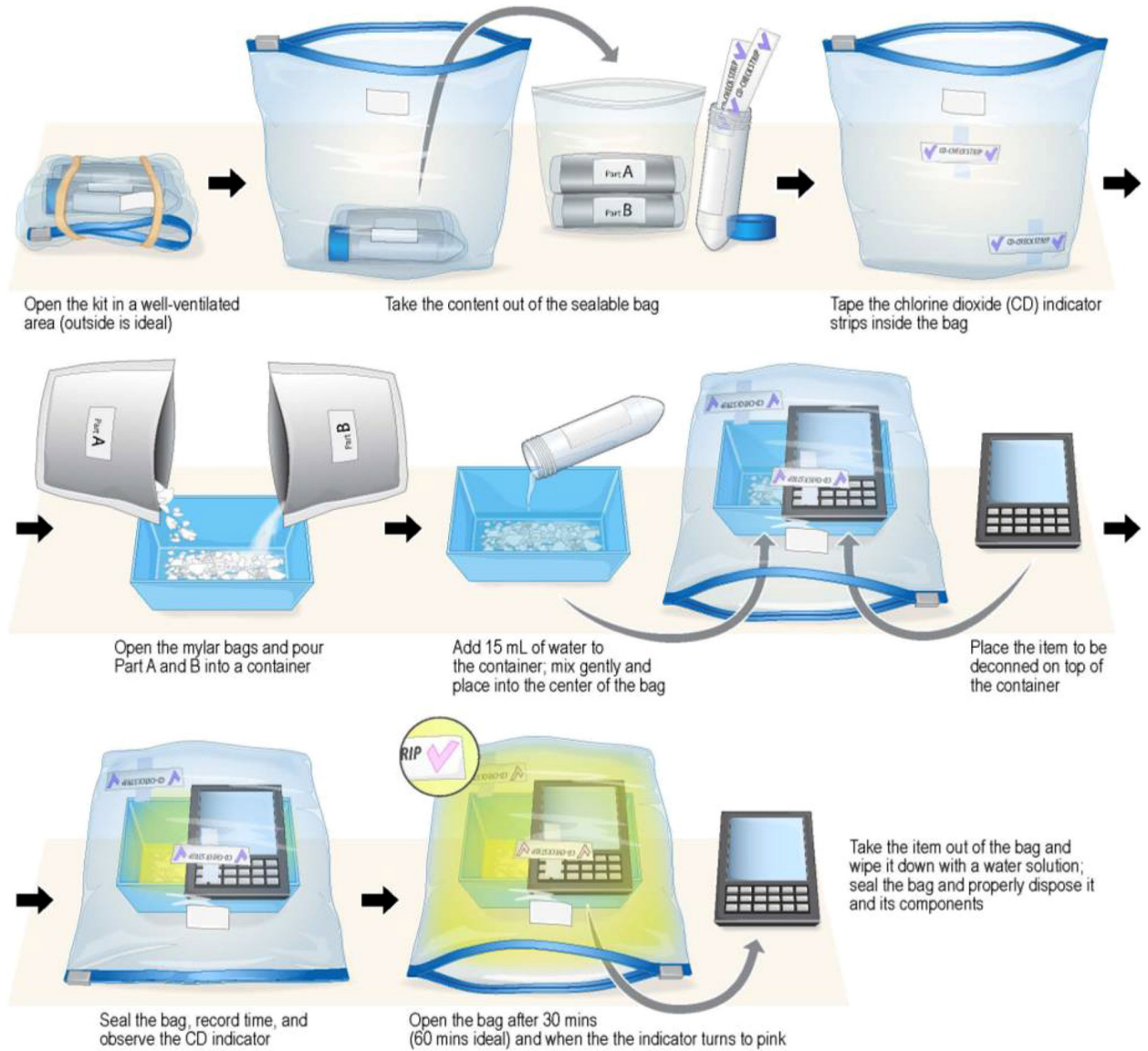

Take the item out of the bag and wipe it down with a water solution; seaperly dispose it and its components

B

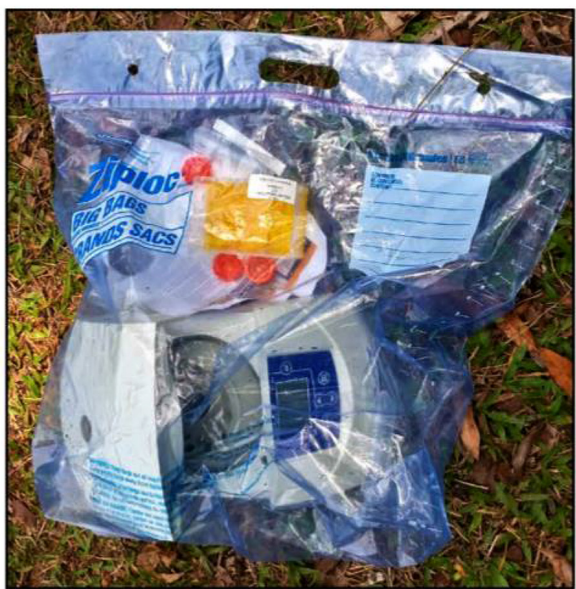

BEFORE the decon

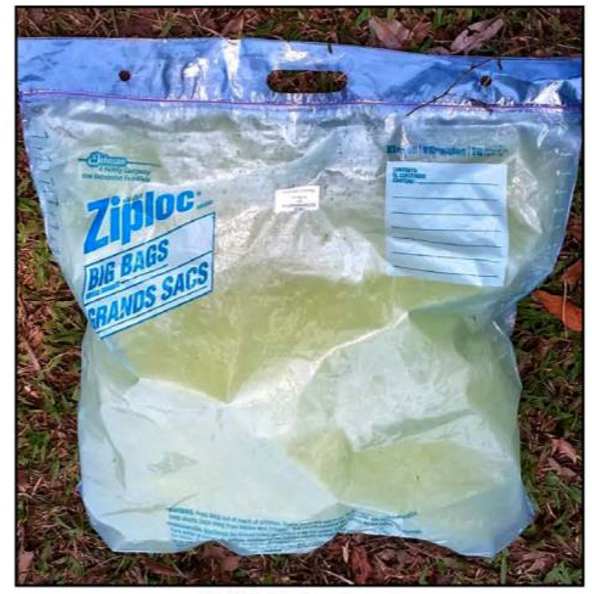

DURING the decon
FIGURE 8 | (A) Diagrammatic representation of steps for using FDKs. Top Row. (i) Open FDK in well-ventilated area (outdoors), (ii) remove contents form sealable bag, and (iii) tape $\mathrm{ClO}_{2}$ indictor strips to inside of bag. Middle Row: (iv) Empty foil pouches of chemical reagents (Part A and Part B) into plastic container, (v) add $15 \mathrm{~mL}$ of water with mixing, and (vi) place plastic container inside bag, then place contaminated medical device on top of container. Bottom Row: (vii) Seal bag, run for 30-60 min, and observe purple $\longrightarrow$ pink color change of $\mathrm{ClO}_{2}$ indicator strip, then (viii) with gloves on, open bag, remove device from bag, and re-seal bag for proper disposal. Caution: when opening bag, gas has a strong odor - avoid inhaling gas. With gloves on, use water to wipe residue from device/equipment (Illustration provided courtesy of Mr. Jiro Wada of $\mathrm{NIH}$ ). (B) Images of an actual decontamination procedure (before and during) of a microcentrifuge with an FDK on the ground in Liberia (Photos courtesy of Dr. Lisa Hensley and Mr. James Pettitt of NIH/NIAID). 
release the trapped gas. The equipment can then be removed and surface-cleaned, since the water, $\mathrm{ClO}_{2}$, and inert salts from the spent reaction can be present on the surface. The remaining solution and materiel can be bagged and disposed of according to local policies.

More than 150 FDKs have been deployed for use by global public health organizations during the Ebola outbreaks in Western Africa, which includes Guinea, Sierra Leone, and Liberia, to protect patients and health care personnel. The FDKs have been used to decontaminate laboratory equipment, POC medical devices and personal cell phones. Overall, the performance has been acceptable and only on occasion have the bags leaked gas during the sterilization cycle, thereby requiring longer exposure times to effectuate the color change of the $\mathrm{ClO}_{2}$ indicator strip and signify exposure sufficient to ensure sterility. For the purpose of field deployment, these kits are safe, compact and easy to ship to remote sites that have limited infrastructure and resources available.

\subsection{Results - Laboratory Testing NIH/NIAID Field Decontamination Kits}

Instructions for the FDKs involve putting Part A and Part B together into a reaction vessel, then adding water. Independent laboratory testing showed that increasing the volume of water slightly and adding the water to the reaction vessel first, followed by adding Part A (oxidant) with stirring, then Part B (reductant) with stirring helped ensure the reaction runs controllably and smoothly, while evolving the maximum amount of $\mathrm{ClO}_{2}$ gas. Small FDKs consist of a 2.5 gallon sealable Mylar bag, $15 \mathrm{~g}$ of Part A, $4 \mathrm{~g}$ of Part B, and $30 \mathrm{~mL}$ of water mixed inside a $100 \mathrm{~mL}$ beaker as the reaction vessel. Large FDKs were scaled proportionately to consist of a 10-gallon bag, $60 \mathrm{~g}$ of Part A, $16 \mathrm{~g}$ of Part $\mathrm{B}$, and $120 \mathrm{~mL}$ of water in a $600 \mathrm{~mL}$ beaker as the reactor vessel. In both configurations, the chemical reaction initiates slowly, then releases copious gaseous $\mathrm{ClO}_{2}$ at $\sim 2 \mathrm{~min}$ and $15 \mathrm{~s}$ after all of the reagents were combined. These reaction compositions with various permutations were run inside the different FDKs (2.5- and 10-gallon bags) and also inside the PCS, using spectrophotometry to monitor $\left[\mathrm{ClO}_{2}\right]$ at $\lambda=360 \mathrm{~nm}$ (the absorbance maximum of $\mathrm{ClO}_{2}$ ) and a combination probe that measures \%RH and temperature simultaneously (6621 Commercial HVAC Temperature/RH Transmitter, Testo, Inc., Sparta, NJ, USA). In addition, the reaction was monitored with $\mathrm{ClO}_{2}$ color-change indicator strips (CD-CHEK, ClorDiSys Solutions, Inc., Lebanon, NJ, USA) and commercially available spore indicators of G. stearothermophilus in Tyvek (ClorDiSys Solutions, Inc., Lebanon, NJ, USA), G. stearothermophilus for steam sterilization (BT Sure, Thermo Scientific, Marietta, $\mathrm{OH}$, USA), and B. atrophaeus for ethylene oxide sterilization (EZ Test, SGM Biotech, Inc., Bozeman, MT, USA). Representative results are summarized in Table 5 using the commercial chemical sets and the three different container units (2.5-gal bag, 10gal bag, and PCS) run for $30 \mathrm{~min}$. In all instances, the CDCHEK strips turned color (indicative of sufficient $\mathrm{ClO}_{2}$ exposure for sterilization) and all of the spore bio-indicators confirmed sterility had been achieved.
TABLE 5 | Laboratory tests of FDKs and the PCS.

\begin{tabular}{|c|c|c|c|c|}
\hline $\begin{array}{l}\text { Test } \\
\text { code }\end{array}$ & Container & Conditions & Observations & $\begin{array}{l}\text { Microbiological } \\
\text { Results }\end{array}$ \\
\hline Test a & 2.5-gal bag & $\begin{array}{l}\text { - } 15 \text { g Part } A \\
\text { - } 4 \text { g Part B } \\
\text { - } 30 \mathrm{~mL} \mathrm{H}_{2} \mathrm{O} \text { (tap) } \\
\text { in a } 100 \mathrm{~mL} \text { beaker }\end{array}$ & $\begin{array}{l}\text { Reaction in 2:20 } \\
\mathrm{RH}>96.4 \% \\
T=30^{\circ} \mathrm{C} \\
{\left[\mathrm{ClO}_{2}\right]>7000 \text { ppm }}\end{array}$ & Sterilized ${ }^{a, b}$ \\
\hline Test h & 10-gal bag & $\begin{array}{l}\text { - } 15 \mathrm{~g} \text { Part } \mathrm{A} \\
\text { - } 4 \mathrm{~g} \text { Part B } \\
\text { - } 30 \mathrm{~mL} \mathrm{H}_{2} \mathrm{O} \text { (tap) } \\
\text { in a } 100 \mathrm{~mL} \text { beaker }\end{array}$ & $\begin{array}{l}\text { Reaction at 2:10 } \\
\mathrm{RH}>74 \% \\
T=25.4^{\circ} \mathrm{C}\end{array}$ & Sterilized ${ }^{a, b}$ \\
\hline Test i & PCS & $\begin{array}{l}\text { - } 16 \text { g Part } A \\
\text { - } 4 \text { g Part B } \\
\text { - } 30 \mathrm{~mL} \mathrm{H}_{2} \mathrm{O} \text { (tap) } \\
\text { in a } 100 \mathrm{~mL} \text { beaker }\end{array}$ & $\begin{array}{l}\text { Reaction at } 2: 30 \\
\mathrm{RH}>90.2 \% \\
T=24.4^{\circ} \mathrm{C} \\
{\left[\mathrm{ClO}_{2}\right]>7000 \mathrm{ppm}}\end{array}$ & Sterilized $^{a, b}$ \\
\hline Test n & PCS & $\begin{array}{l}\text { - } 15 \mathrm{~g} \text { Part } \mathrm{A} \\
\text { - } 4 \mathrm{~g} \text { Part } \mathrm{B} \\
\text { - } 30 \mathrm{~mL} \mathrm{H}_{2} \mathrm{O} \text { (tap) } \\
\text { in a } 100 \mathrm{~mL} \text { beaker }\end{array}$ & $\begin{array}{l}\text { Reaction at } 2: 12 \\
\mathrm{RH}>93.5 \% \\
{\left[\mathrm{ClO}_{2}\right]>7000 \mathrm{ppm}} \\
\text { Run time } 15 \mathrm{~min}\end{array}$ & Sterilized $^{\mathrm{a}, \mathrm{b}}$ \\
\hline
\end{tabular}

a,b Sterility confirmed with G. stearothermophilus and B. atrophaeus bio-indicators, respectively.

\subsection{Results - Decontamination of Textiles}

Some textile technologies have certain material properties with the potential to self-decontaminate by inactivating biological hazards (B. anthracis spores) and/or chemical agents on their surfaces, thus making them a form of novel decontamination technology. Other types of textiles require external applications to remove biological and chemical hazards, such as the use of sorbents to remove chemical agents or the use of cold sterilants (bleach, chlorine dioxide, etc.) to safely inactivate biological hazards.

Natick Soldier RD\&E Center's novel decontamination technologies (Table 1) have also been applied in the decontamination of textiles using live cultures of $B$. anthracis Delta Sterne as a surrogate for B. anthracis. Specifically, NSRDEC's “D-FEND ALL" technology was used to create 20-200 ppm $\mathrm{ClO}_{2}$ solutions that completely inactivated 7.5 logs of $B$. anthracis Sterne inoculated onto two different types of fabrics (a nylon-cotton blend and an experimental weatherproof fabric) within $10 \mathrm{~min}$ (minor bleaching of the weatherproof fabric occurred at only the $200 \mathrm{ppm} \mathrm{ClO}_{2}$ solution). Other experimental fabrics were inoculated with $B$. anthracis Delta Sterne spores, then subjected to either (i) $30 \mathrm{~min}$ rinse in bleach (5-6\% aqueous $\mathrm{OCl}^{-}$), (ii) gaseous $\mathrm{ClO}_{2}$ using NSRDEC's NCC and PCS technologies (Table 1), or (iii) HPP. In all cases, the decontamination treatments achieved a $100 \%$ spore kill on the fabric samples (a 6.59-, 5.73-, and 6.13-log kill for bleach, gaseous $\mathrm{ClO}_{2}$, and $\mathrm{HPP}$, respectively). For HPP experiments, inoculated fabric samples were treated with conditions of pressure $=550 \mathrm{MPa}$, temperature $=65^{\circ} \mathrm{C}$, and time $=100 \mathrm{~min}$.

\subsection{Results - AFM Characterization of Morphological and Structural Attributes of Bacillus spores}

Atomic force microscopy can be used to analyze high-resolution architecture, assembly, structural dynamics, and function of dormant and germinating spores of various wild type and mutant 
Bacillus (Plomp et al., 2005a,b,c, 2007a, 2014; Carroll et al., 2008; Ghosh et al., 2008; Plomp and Malkin, 2009; Malkin and Plomp, 2010; Malkin, 2011; Elhadj et al., in preparation) and Clostridium species (Plomp et al., 2007b). Specifically, AFM has been used to directly visualize and analyze spore morphological, dimensional, and high-resolution coat structural attributes, and these results demonstrated that spore morphological and coat structures are phylogenetically (Plomp et al., 2005a,b,c, 2014) and growth medium (Malkin, 2011; Elhadj et al., in preparation) dependent. We have found that strikingly different speciesdependent spore coat structures are a consequence of nucleation and crystallization mechanisms that regulate the assembly of the outer spore coat (Plomp et al., 2005a,b,c, 2007b; Malkin and Plomp, 2010). Spore morphological, dimensional, and structural attributes could serve as a baseline for assessing the effects of sterilization and/or decontamination treatments on the morphological and structural integrity and the ultra-structural damage of spores treated by irradiation or $\mathrm{ClO}_{2}$.

\subsubsection{AFM Characterization of $\gamma$-Irradiated Bacillus Spores}

\subsubsection{Native air-dried Bacillus spore}

Size distributions (spore height/width and length) from large populations (several 100s) of air-dried solution- and agargrown spores were determined for spores of $B$. atrophaeus, B. thuringiensis, B. subtilis (Plomp et al., 2005a) and B. anthracis spores (Elhadj et al., in preparation), with more than 30 spore preparations being utilized for the assessment of $B$. anthracis spore dimensional attributes (Elhadj et al., in preparation). Representative results are compiled in Table 6.

Typical AFM images of B. anthracis Sterne and B. thuringiensis spores are presented in Figures $\mathbf{9 A , B}$, respectively. The corresponding optical phase microscopy is shown in (Figures 9C,D), demonstrating that these spores are phase bright (refractile, ungerminated). The vast majority of spores (Figures 9A,B) are intact with heights within ranges indicated in Table 6 and exhibiting surface ridges (some indicated with white arrows) extending along the long axis of the spore. These ridges are the characteristic attribute of air-dried Bacillus spores (Plomp et al., 2005a,b,c, 2014) and appear due to coat folding caused by changes in spore size upon dehydration (Driks, 2003; Westphal et al., 2003; Plomp et al., 2005a). Occasionally, collapsed spores (as one indicated with a black arrow in Figure 9A) with heights in the range of $200-500 \mathrm{~nm}$ are observed in the spore preparations.

TABLE 6 | Spore height determinations.

\begin{tabular}{lll}
\hline Spore species & $\begin{array}{l}\text { Spore height air-dried } \\
\text { (solution-grown) }\end{array}$ & $\begin{array}{l}\text { Spore height air-dried } \\
\text { (agar-grown) }\end{array}$ \\
\hline Bacillus thuringiensis* $^{*}$ & $\begin{array}{l}750-1000 \mathrm{~nm} \\
\mathrm{avg} \approx 872 \mathrm{~nm}\end{array}$ & $\begin{array}{l}740-1080 \mathrm{~nm} \\
\text { average } \approx 937 \mathrm{~nm}\end{array}$ \\
& $(\mathrm{AD}=5.4 \%)$ & $(\mathrm{AD}=5.3 \%)$ \\
B. anthracis $^{*}$ & $800-880 \mathrm{~nm}$ & $750-800 \mathrm{~nm}$ \\
& average $\approx 835 \mathrm{~nm}$ & average $\approx 780 \mathrm{~nm}$ \\
& $(\mathrm{AD}=5.4 \%)$ & $(\mathrm{AD}=5.4 \%)$ \\
\hline
\end{tabular}

*Plomp et al., 2005a; *Elhadj et al., in preparation.
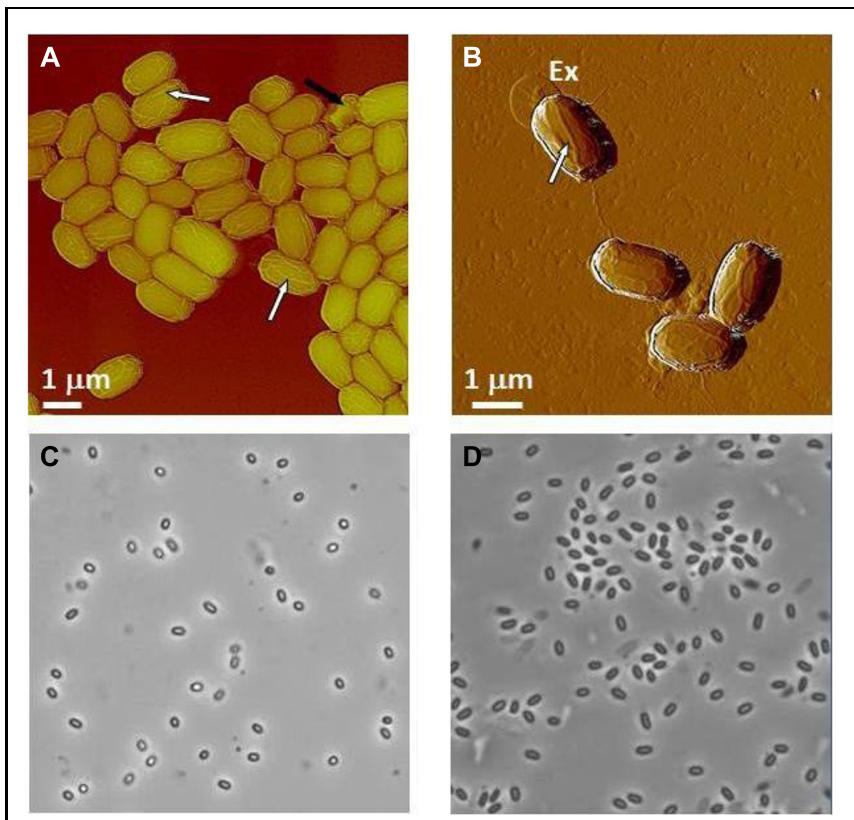

FIGURE 9 | Characterization of Bacillus spores. (A,B) AFM images of native air-dried spores. (A) Height image of $B$. anthracis Sterne spores and (B) amplitude image of $B$. thuringiensis spores. In both images surface ridges extending along the entire length of spores (several surface ridges noted by white arrows) are seen. In (A) a collapsed spore is indicated with a black arrow. In (B) an exosporia is indicated with Ex. (C,D) Phase contrast microscopy images of $B$. anthracis Sterne spores $(\mathbf{C})$ and $B$. thuringiensis spores (D)

This phenomenon could be attributable to partial germination, and subsequent partial collapse of the germinated spore upon air drying due to germination-induced internal structural changes.

\subsubsection{2. $\gamma$-Irradiated Bacillus spores}

Dauphin et al. (2008) reported that subjecting virulent B. anthracis spores at a concentration of $10^{7} \mathrm{CFU} / \mathrm{ml}$ to a dose of $2.5 \times 10^{6}$ rads results in complete spore inactivation (sterilization). The spore images shown below in Figures $\mathbf{1 0}$ and $\mathbf{1 1}$ were certified as sterilized for shipping and likely to have received a standard dose higher than $2.5 \times 10^{6}$ rads to assure sterility. Specifically, we characterized $\gamma$-irradiated B. anthracis Ames spore samples produced on nutrient sporulation medium (NSM) agar, Nutrient agar-BBL, Mueller Hinton-BBL, and brain heart infusion (BHI)-BBL using AFM imaging and demonstrated that upon dehydration, as illustrated in Figure 10, the architecture of these spores collapsed. AFM examination of irradiated spores prepared as air-dried samples revealed further pronounced morphological and structural differences from native spores (Figures 9A,B). As illustrated in Figure 11, air-dried samples of $\gamma$-irradiated spores comprised partially collapsed spores (PCSs), spore coat remnants (SCRs), and exosporia remnants (ERs). The heights of PCS were in the range of $400-600 \mathrm{~nm}$, which is significantly lower than the height of an air-dried non-irradiated native spores (Table 6). The thickness of SCR and ER was in the range of 100-250 

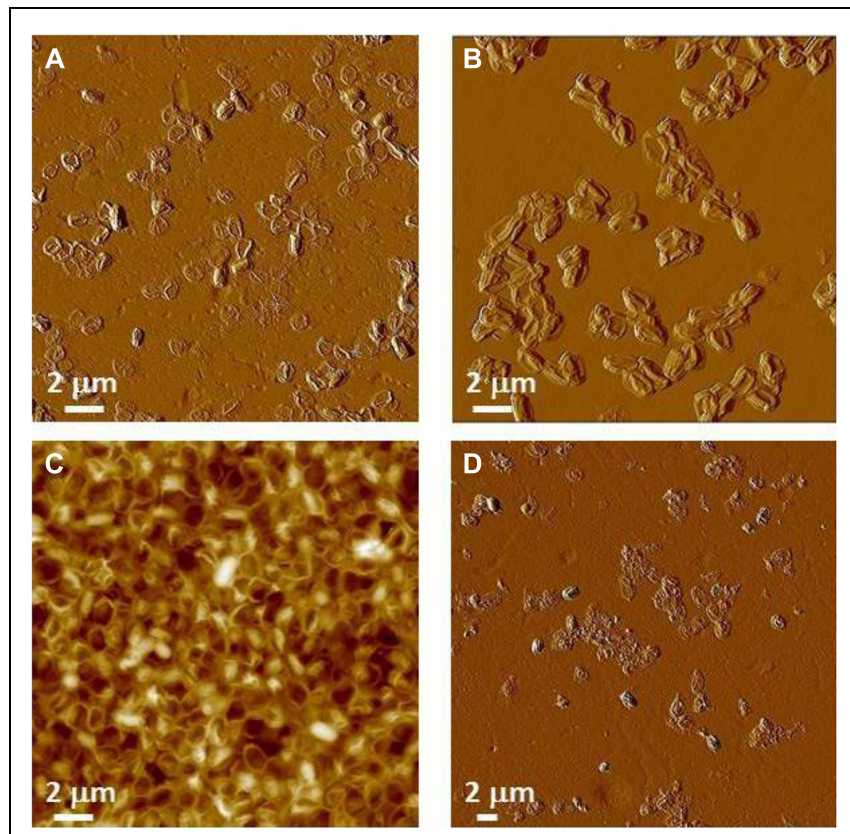

FIGURE 10 | Atomic force microscopy (AFM) images $\gamma$-irradiated (standard dose $\geq 2.5 \times 10^{6}$ rads to assure sterility) air-dried B. anthracis Ames spores. (A) Spores produced on Mueller Hinton-BBL; (B) spores produced on NSM agar; (C) spores produced on nutrient agar-BBL; and (D) spores produced spores produced on BHI-BBL.

and 40-45 $\mathrm{nm}$ respectively, which are comparable with the dimensions of native spore coats and exosporia. Only a small proportion of the air-dried samples of $\gamma$-irradiated $B$. anthracis Ames spores were present as intact spores (IS, Figure 11D) exhibiting heights equal to non-irradiated air-dried B. anthracis spores.

These studies demonstrated that exposure to sterilizing $\gamma$-irradiation produced profound structural changes in B. anthracis spores. Irradiation damages spore internal structural integrity (membranes, cortex etc.) and causes either partial (PCS) or complete (SCR) evacuation of the spore core. It is likely that in the hydrated sample, internal spore components that have sustained damage from the irradiation treatment (protein, DNA, ribosomes, small molecules, etc.) have partially/or completely diffused from the spore core into the bulk liquid phase. Note, that the leakage of spore core contents into the bulk media could also adversely affect biochemical and chemical analysis of the collected irradiated sample. Because of the significant internal structural damage induced by irradiation, the dehydration of irradiated spores suspended in liquid resulted in their collapse (Figures 10 and 11).

There was an excellent cross-correlation between phase contrast optical microscopy and AFM in the characterization of the irradiated spore samples. Thus, as seen in Figure 12, phase contrast microscopy demonstrated that the vast majority of spores in irradiated samples were either phase dark, which corresponds to the evacuation of the spore coat, or spore ghosts, which corresponds to SCRs.
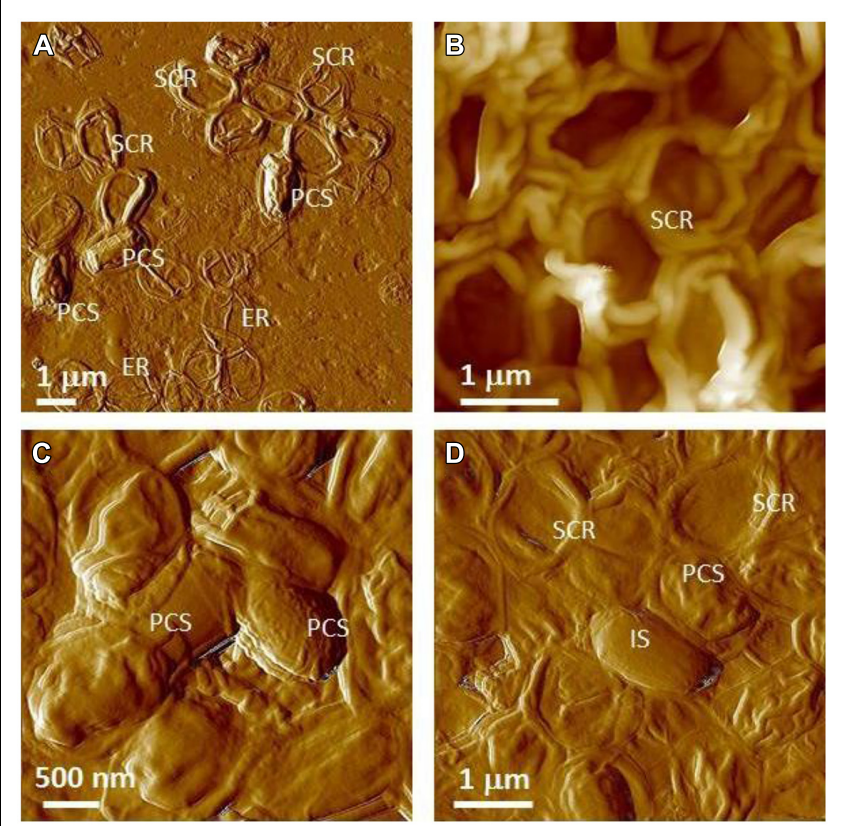

FIGURE 11 | Atomic force microscopy examination of $\gamma$-irradiated ( $\geq 2.5 \times 10^{6}$ rads) B. anthracis Ames spore air-died samples. (A) Spores produced on Mueller Hinton-BBL; (B) spores produced on NSM agar; (C,D) spores produced on nutrient agar-BBL. (A-D) are amplitude and height AFM images respectively.
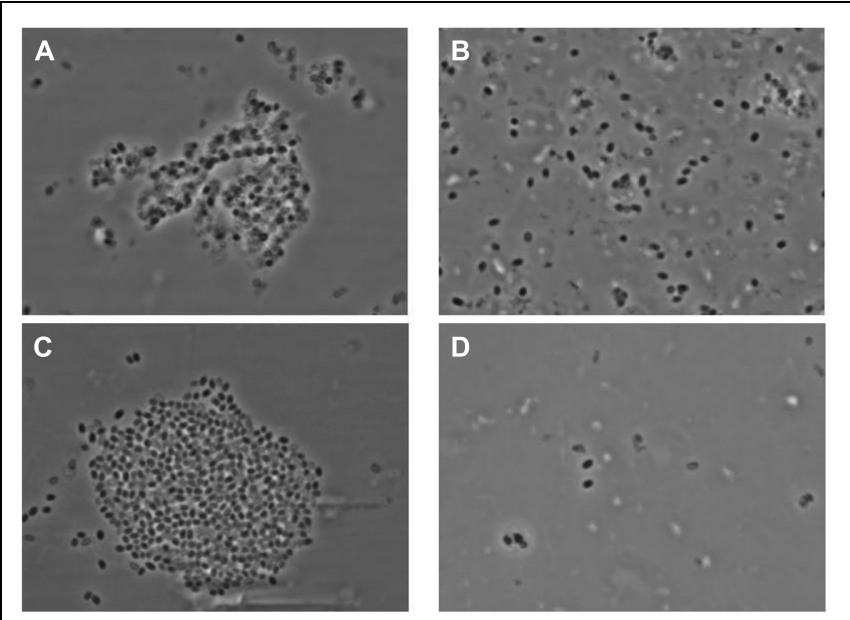

FIGURE 12 | Phase contrast microscopy images of $\gamma$-irradiated $\left(\geq 2.5 \times 10^{6}\right.$ rads) Bacillus anthracis Ames spores (A) produced on Mueller Hinton-BBL, (B) produced on NSM agar, (C) produced on nutrient agar-BBL, and (D) produced BHI-BBL.

With AFM of air-dried spores for $\gamma$-irradiated B. thuringiensis spores, similar types of ultrastructural damage and collapse have been observed (Figure 13). These samples comprise PCS with heights in the range of $30-40 \%$ of the height of non-irradiated native air-dried B. thuringiensis spores (Table 6, Plomp et al., 2005a). 

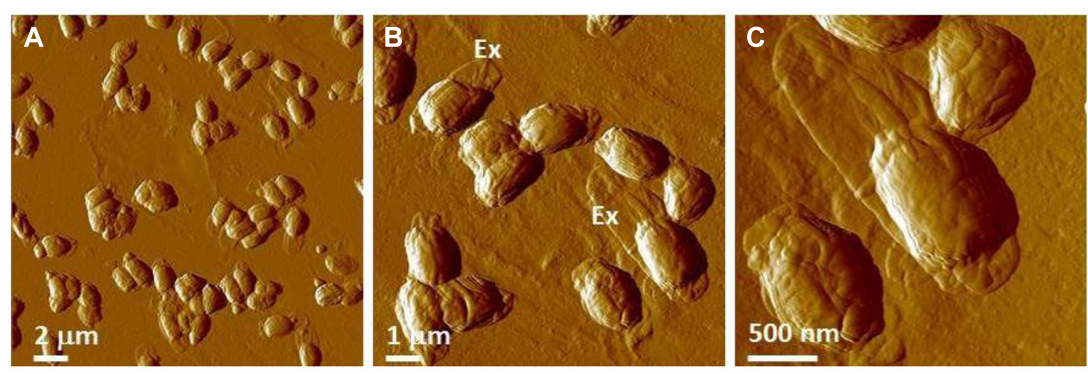

FIGURE 13 | AFM images of $\gamma$-irradiated ( $\geq 2.5 \times 10^{6}$ rads) B. thuringiensis spores in (A) a low magnification AFM image. In a higher magnification AFM image (B), exosporia (denoted with Ex) are observed. Image (C) is a close-up image taken of the lower right area in panel (B).
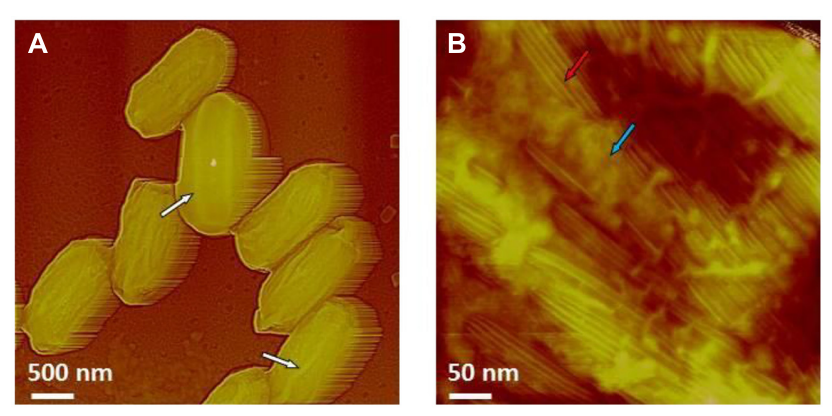

FIGURE 14 | (A,B) AFM images of $B$. atrophaeus spores exposed to a sterilization (6-log kill) dose of $\mathrm{ClO}_{2}$ (500 ppm $\times 5 \mathrm{~h}=2500 \mathrm{ppm}-\mathrm{h}$ ). In (A) surface ridges extending along the entire length of spores (several surface ridges noted by white arrows) are seen. In (B) high-resolution AFM image showing the regular rodlet structure (red arrow) and patches of an amorphous outermost layer (blue arrow), both characteristic to native, air dried B. atrophaeus spores.

\subsubsection{AFM Characterization of Chlorine Dioxide-Treated Bacillus Spores}

Chlorine dioxide is sporicidal and a well-known decontamination regime for spores of $B$. anthracis. As illustrated in Figure 14, B. atrophaeus spores exposed to sporicidal levels of chlorine dioxide (dose $=2500 \mathrm{ppm}-\mathrm{h}$ ) remain intact upon air-drying. The height of the chlorine dioxide-treated spores varies in the range of 500-650 nm, which corresponds well with the height of native air-dried B. atrophaeus spores (Plomp et al., 2005a). Similarly, the morphology of $\mathrm{ClO}_{2}$-treated $B$. atrophaeus spores is indistinguishable from the morphology of untreated spores with pronounced surface ridges seen in Figure 9A. Furthermore, $\mathrm{ClO}_{2}$ is a selective oxidant affecting cysteine, tryptophan and tyrosine amino acids in proteins and is not expected to grossly alter spore coat ultrastructure. Indeed, the high-resolution spore coat architecture and topology of $\mathrm{ClO}_{2}$-treated spores is unaltered in character from those of native air-dried spores (Plomp et al., 2005a,b,c, 2014), with rodlet coat structures and patches of an amorphous outermost layer clearly seen (Figure 14B).

\subsubsection{AFM Characterization of Spore Responses in the Fully Hydrated vs. Air-Dried State}

Atomic force microscopy allows a direct comparison of fully hydrated and air-dried native spores visualized under water and in air, respectively. Particularly, AFM studies of fully hydrated B. atrophaeus (Plomp et al., 2005a, 2007a), B. anthracis (Plomp and Malkin, unpublished results) and Clostridium novyi NT spores (Plomp et al., 2007b) demonstrated that high-resolution attributes (i.e., rodlet, honeycomb, and inner coat layer structures), maintained the same patterns, lattice periodicities, and step heights as seen with air-dried spores (Plomp et al., 2005a,b,c, 2007b, 2014; Elhadj et al., in preparation). Furthermore, the ability of the coat to fold and unfold concomitant with changes in spore size was suggested (Driks, 2003; Westphal et al., 2003) based on measurements of $B$. thuringiensis spore dimensions induced by humidity transients. Images of a fully hydrated $B$. atrophaeus spores are presented in Figure 15A. Surface ridges, the prominent structural features of air-dried spores (Figure 9), are typically absent from the surface of fully hydrated spores (Figure 15A). The direct visualization of 35 individual spores was performed to probe the dynamic response of their aqueous to aerial phase transition (Plomp et al., 2005a). Spores were visualized under water, then air-dried for $\sim 40 \mathrm{~h}$ and imaged in air $(65 \%$ $\mathrm{RH}$ ), then re-imaged after rehydration. Typical examples of hydration/dehydration ultrastructural transitions are presented in Figures 15A,B. As illustrated in Figure 15A, the coat of a fully hydrated spore appears to be tightly attached to the cortex and upon dehydration (Figure 15B) forms an $\sim 50 \mathrm{~nm}$ surface ridge/fold extending along the entire length of the spore.

The changes in spore surface architecture with dehydration were accompanied by a decrease in spore size. As illustrated in Figure 15C, the average width/height of 35 individual air-dried spores was reduced to $88 \%$ of the size measured for fully hydrated spores. The rehydration of air-dried spores, by placing them in water for $2 \mathrm{~h}$, restored the spores to $97 \%$ of their original size, thereby establishing the reversibility of the size transition concurrent with rehydration (Figure 15C).

The observed decrease in the width of bacterial spores with dehydration is apparently due to the contraction of 


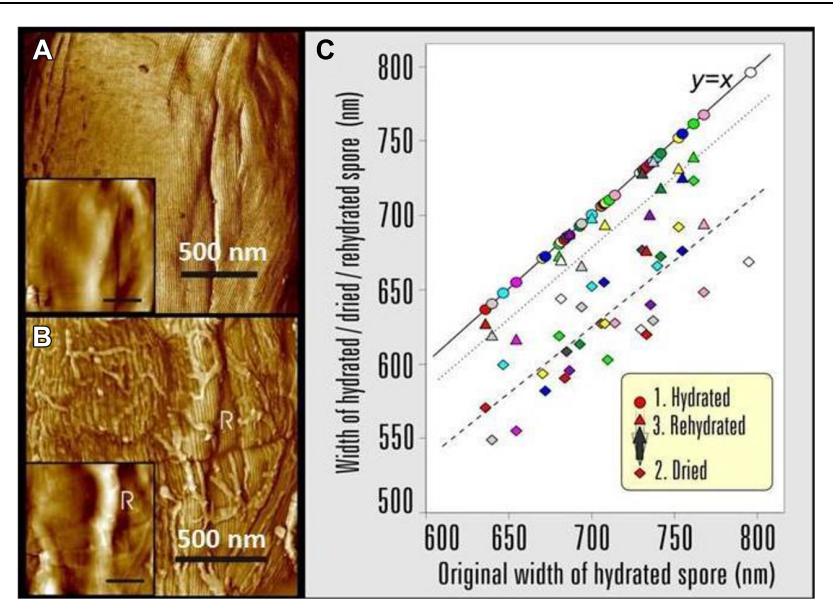

FIGURE 15 | AFM images showing the effects of changing the B.atrophaeus spore environment form hydrated to dehydrated states. (A) Phase image and height image (inset) detail of a $B$. atrophaeus spore in water, showing rodlet spore coat structure and several shallow wrinkles. (B) The same spore after drying, showing rodlet structure (with many adsorbed stray rodlets, which sedimented from the bulk solution upon drying of the sample) and a 60-nm high ridge (indicated with R). The graph (C) shows spore width variations of 35 individual $B$. atrophaeus spores, as a function of the size of the originally hydrated spore, followed by dehydration ( $24 \mathrm{~h}$; diamonds, dashed trend line), then rehydration ( $2 \mathrm{~h}$; triangles, dotted trend line). For ease of comparison, the original hydrated spore width is (redundantly) depicted as circles, which by definition lie on the solid $y=x$ line. Thus, the three data points for one individual spore, depicted with the same color, are all on the same vertical line. Several spores detached from a substrate during rehydration experiments resulting in a smaller amount of experimental rehydration points (triangles). On average, spore size is reduced to $88 \%$ for dried spores, and returns to $97 \%$ of the original width for rehydrated spores. Images reproduced, with permission from Plomp et al. (2005a), Copyright () (2005). The Biophysical Society. Published by Elsevier, Inc.

the spore core and/or cortex. The spore coat itself does not shrink/expand but is flexible enough to compensate for the internal volume decrease of core/cortex compartments by surface folding and the formation of ridges. These studies establish that dormant spores are dynamic physical structures, which exhibit profound morphological and structural responses with changes in its natural environment. These changes play important roles in selecting and implementing successful decontamination strategies.

\subsection{Bio-indicators for the Inactivation of Bacillus spp. Spores by $\mathrm{ClO}_{2}$ Gas}

As a gas-phase sporicide, $\mathrm{ClO}_{2}$ has advantages over other gasphase sterilizing agents that leave residues or may pose health hazards (Bruch, 1973; Dolovich et al., 1984; Chapman et al., 1986; Lettman et al., 1986; Lykins et al., 1994; Muttamara et al., 1995). The efficacy of $\mathrm{ClO}_{2}$ decontamination treatments are typically verified through the use of spore BIs. We present extensive statistical analysis and modeling results that can be used to predict survival probabilities for three species of spores at varying doses of $\mathrm{ClO}_{2}$ by analyzing its effectiveness to kill 6 logs of bacterial spores (sterilize). Our analysis includes four lots of B. atrophaeus spore strips with different Decimal reduction (D) values, which are the times to reduce surviving spores by $90 \%$, for ethylene oxide $\left(\mathrm{D}_{\mathrm{EtO}}\right)$ to allow their use as BI's to monitor process efficacy in large-scale emergency decontamination efforts, as well as the spores of G. stearothermophilus and B. thuringiensis, a close relative of $B$. anthracis. Parameters contributing to the efficacy of spore sterilization by $\mathrm{ClO}_{2}$ include, but are not limited to, $\mathrm{ClO}_{2}$ concentration, $\mathrm{RH}$, temperature, exposure time, and the $\mathrm{BI}$ packaging materials.

The data in Figures 5A-D clearly demonstrate that the probability, with a confidence level of $95 \%$, of a spore surviving greatly diminishes as dose increases. In fact, the correlation between increasing $\left[\mathrm{ClO}_{2}\right]$ and sporicidal activity is strong for all species and lots tested. At a constant spore strip population $\left(1.2 \times 10^{6}\right)$, exposure time, and $\% \mathrm{RH}(79 \%)$, the percent of spore strips killed increases (probability of a spore surviving decreases) as a function of increasing dose (dose $\equiv \mathrm{ppm}$ $\mathrm{ClO}_{2} \times$ exposure time) as the gas concentration increases (Figures 5A,B). Similarly, we have also found that for a constant $\left[\mathrm{ClO}_{2}\right], \mathrm{RH}$, and spore population, increasing the dose by increasing the exposure time also results in higher levels of kill (lower probability of survival, Figures 5C,D).

A particular point of interest is the dose at which the predicted spore survival probability is at most $10^{-6}$ (the EPA target) with $95 \%$ confidence. If we consider species $B$. atrophaeus as an example, for which there is a $D_{\text {EtO }}$ value of 3.1 or 5.0 , an $\mathrm{RH}$ of 0.79 , and take the number of spores to be $10^{6}$ (not stratifying by packaging), then the dose at which a 6-log drop is achieved is, with $95 \%$ probability, between 268 and 592 or between 628 and $822 \mathrm{ppm}$-h, respectively (data not shown), which is significantly less than the dose of $2500 \mathrm{ppm}-\mathrm{h}$ required in some whole building decontaminations. This suggests that a lower $\mathrm{D}_{\mathrm{EtO}}$ value correlates with a greater susceptibility to $\mathrm{ClO}_{2}$, a phenomenon that we also (see graphically in Figures 6A-D). Though $B$. atrophaeus spores are accepted as a standard test organism for sterility (Rosenblatt et al., 1987), the strains of G. stearothermophilus and B. thuringiensis spores assayed required higher $\mathrm{ClO}_{2}$ doses (at $0.79 \mathrm{RH}$ ), between 1235-2415 and 1497-2063 ppm-h, respectively, to achieve the same spore survival probability $\left(\leq 10^{-6}\right)$ with $95 \%$ confidence (Figures 5A,B).

With $\left[\mathrm{ClO}_{2}\right]=500$ or $1000 \mathrm{ppm}$ and exposure time fixed at $4 \mathrm{~h}$, we varied the $\% \mathrm{RH}(40-90 \%)$ of the exposure chamber to assess the bioeffects of humidified $\mathrm{ClO}_{2}$ on two lots of B. atrophaeus BI's with $\mathrm{D}_{\mathrm{EtO}}$ values of 3.3 and 3.8 (Figures 6C,D, respectively). We found, in general, that increasing $\% \mathrm{RH}$ at a given dose increases the level of kill (Figures 7A,B). Additionally, to achieve equivalent levels of kill at a fixed $\mathrm{ClO}_{2}$ dose, higher $\mathrm{RH}$ is required for $B$. atrophaeus strips with a higher $\mathrm{D}_{\mathrm{EtO}}$ value (Figures 7A,B). In general, we found that RH levels of $\geq 80 \%$ are optimal for $\mathrm{ClO}_{2}$ sporicidal bioeffects over a wide range of doses.

The humidity dependence of $\mathrm{ClO}_{2}$ sterilization may be twofold. Increasing RH results in an increase in localized sorption of water molecules on the spore surface, causing the spore to swell and hypothetically resulting in increased pore size through which $\mathrm{ClO}_{2}$ can pass (Westphal et al., 2003). $\mathrm{ClO}_{2}$ partitioning from the gas phase into aqueous solution is about 
1:40, and it has been reported that $\mathrm{ClO}_{2}$, a radical, is a dissolved gas in solution (Aieta and Berg, 1986; Simpson et al., 1993). Therefore, as $\mathrm{RH}$ increases, thus does the local concentration of $\mathrm{ClO}_{2}$, and the spore becomes more swollen, perhaps more readily passing water and its associated dissolved $\mathrm{ClO}_{2}$ gas through opened channels. Other authors have reported a similar relationship between increased $\mathrm{RH}$ during $\mathrm{ClO}_{2}$ treatment with increased mortality of vegetative bacterial cells (Han et al., 1999, 2001).

We consistently observed no statistically significant difference in spore killing between BI's packaged in 1059B medical grade Tyvek versus no packaging (Figures 5-7). Identical lots of $B$. atrophaeus $\log 6$ spore strips, 1161841 and 1161911, with $\mathrm{D}_{\mathrm{EtO}}$ values of 3.3 and 3.8 , respectively, and packaged by the manufacturer in their standard and industry-accepted medical grade glassine, yielded grossly inconsistent results when exposed to a wide range of $\mathrm{ClO}_{2}$ doses (data not shown) - at 2000 ppm-h and $80 \% \mathrm{RH}, 90 \%$ of the spore strips (lot 1161841) were killed when packaged in Tyvek and there was no effect on the strips packaged in glassine (Figure 7C). A much greater dose ( 20,000 ppm-h) was required to kill $100 \%$ of the B. atrophaeus strips packaged in glassine (Figure 7D). Figure $7 \mathrm{E}$ shows predicted probabilities of a spore remaining live after treatment, for Tyvek and no packaging, for all three species (two different $\mathrm{D}_{\mathrm{EtO}}$ values for $B$. atrophaeus) and with $\mathrm{RH}=0.79$ and the number of spores fixed at $N=10^{6}$.

\section{Bacterial Spore Properties - Mechanisms of Resistance and Killing}

The novel $\mathrm{ClO}_{2}$ decontamination technologies mentioned above are laboratory inventions that were patented, commercialized, and adapted for actual field use in austere environments (e.g., far-forward military deployments or global humanitarian relief in third-world countries, etc.). The FDKs were adapted from the COTS version of NSRDEC's decontamination technologies and became an important contributor for global public health organizations (MSF, WHO, Public Health Canada, $\mathrm{NIH}$ ) in sterilizing Ebola-contaminated medical equipment and preventing the spread of disease at remote clinical sites in West Africa. All decontamination technologies have to be validated for efficacy in the laboratory and during their actual field use. Lethal chemical agents typically inactivate viruses by damaging the protein capsid or DNA (Kingsley et al., 2014). While the Ebola virus itself is an enveloped virus and relatively fragile, the virus is classified as Biosafety level 4 (BSL-4) due to the severity of disease it causes in humans, and presently there is no standard test assay for the Ebola virus under representative conditions even in a high-level containment facility. Bacterial spores, therefore, provide the standard assay for assuring sterility with deployed FDKs and other decontamination technologies, because of the extreme resistance of bacterial spores to chemical (and other) decontamination methods. Consonant thereto, we review bacterial spore properties, structures, and resistance mechanisms and focus on the mechanisms through which
$\mathrm{ClO}_{2}$ inactivates bacterial spores as the indicators of efficient bio-decontamination.

\subsection{Bacterial Spores - Background}

Members of bacteria of Bacillus and Clostridium species and their close relatives can form metabolically dormant spores, generally when the environment no longer can support growth (Setlow, 2006; Leggett et al., 2012; Setlow and Johnson, 2012). Spores are extremely resistant to all manner of harmful treatments, and can remain dormant for years. However, if given the proper stimuli, generally nutrients such as amino acids or sugars, spores can return to life in minutes and outgrow into vegetative cells (Setlow, 2013). During subsequent growth, the growing or stationary phase cells of some spore-formers can secrete toxins or deleterious enzymes, and these agents can cause food spoilage or food poisoning and other human or animal diseases. As a consequence, there is much interest in the mechanisms of spore resistance to and the killing of spores by different treatments including high pressure, radiation, chemicals, plasma, or heat. One factor that is often overlooked in thinking about these mechanisms is the significant heterogeneity in properties of individual spores in genetically homogeneous spore populations, and this is seen in levels of spore resistance and in rates of spore germination (Setlow et al., 2012). The reasons for some of this heterogeneity are known, in particular some of the causes of the variability in rates of germination between individual spores. However, the reasons for the variability in resistance properties between individual spores in populations are not clear.

\subsection{Spore Structure, Components, Properties, and their Role(s) in Spore Resistance}

A number of novel spore structures and many spore-specific components and features are crucial for imparting various spore resistance properties (Table 7). Spores of all species appear to have a generally similar basic structure (Figure 16), with the exception of the outermost exosporium layer that is present in spores of some species, but not all (Gerhardt, 1967; Henriques and Moran, 2007; Driks, 2009; McKenney et al., 2013). The large balloon-like exosporium is composed of proteins, sugars, and lipid, and it is present in many spore formers that can cause disease, including the members of the Bacillus cereus group and Clostridium difficile, but is absent from the model spore former B. subtilis. This structure appears to be important in spore adhesion properties, and in restricting access of antibodies to the spore coat layer below the exosporium, but plays no major role in most spore resistance properties (Setlow, 2006; Henriques and Moran, 2007). The exosporium may also play some role in virulence of spores, but this role is not yet clear.

Moving from the exterior inward, the spore coat is found under the exosporium, and is composed of many spore-specific proteins assembled in a number of layers (Henriques and Moran, 2007; McKenney et al., 2013). The coat can contain up to $50 \%$ of total spore proteins, and protects more inner spore layers such as peptidoglycan from attack by lytic enzymes such as lysozyme, and also by lytic enzymes of predatory eukaryotes. The coat is also probably crucial in the resistance of spores to a variety of chemicals, including chlorine dioxide 
TABLE 7 | Mechanisms of spore killing by and resistance to various agents*.

\begin{tabular}{|c|c|c|}
\hline Type of agent & Mechanisms of killing & $\begin{array}{l}\text { Mechanisms of } \\
\text { resistance }\end{array}$ \\
\hline HPP & Probably protein damage & $\begin{array}{l}\text { Low core water } \\
\text { content }\end{array}$ \\
\hline $\begin{array}{l}\text { UV, } \gamma \text {-radiation, nitrite, } \\
\text { formaldehyde }\end{array}$ & DNA damage & $\begin{array}{l}\alpha / \beta \text {-type SASP, DNA } \\
\text { repair, and perhaps IM } \\
\text { impermeability }\end{array}$ \\
\hline $\begin{array}{l}\text { Oxidizing agents } \\
\left(\mathrm{OCl}^{-}, \mathrm{ClO}_{2}, \mathrm{O}_{3}\right)\end{array}$ & IM damage & $\begin{array}{l}\text { Spore coat/outer } \\
\text { membrane }\end{array}$ \\
\hline $\mathrm{H}_{2} \mathrm{O}_{2}$ & Probably core protein damage & $\begin{array}{l}\alpha / \beta \text {-type SASP, low } \\
\text { core water }\end{array}$ \\
\hline $\begin{array}{l}\mathrm{OH}^{-} \text {, wet heat, some } \\
\text { oxidizing agents }\end{array}$ & Inability to germinate & $\begin{array}{l}\text { Spore coat/outer } \\
\text { membrane }\end{array}$ \\
\hline Strong mineral acid & Explosive rupture of IM & Not studied \\
\hline Plasma & Protein or DNA damage ${ }^{1}$ & $\begin{array}{l}\alpha / \beta \text {-type SASP, spore } \\
\text { coat, DNA repair }\end{array}$ \\
\hline Wet heat & Protein damage & $\begin{array}{l}\alpha / \beta \text {-type SASP, low } \\
\text { core water content }\end{array}$ \\
\hline Dry heat & DNA damage & $\begin{array}{l}\alpha / \beta \text {-type SASP, DPA, } \\
\text { DNA repair }\end{array}$ \\
\hline
\end{tabular}

*Data for these conclusions are from Gerhardt and Marquis (1989), Setlow (1994,2001,2006; 2007a), Coleman et al. (2007, 2010), Leggett et al. (2012), Setlow and Johnson (2012), Reineke et al. (2013a,b), Moeller et al. (2014), Setlow et al. (2014).

${ }^{1}$ Plasma with UV-C kills spores by DNA damage, while UV-C free plasma likely kills by protein damage.

$\left(\mathrm{ClO}_{2}\right)$ and sodium hypochlorite (bleach, $\left.\mathrm{OCl}^{-}\right)$, that are widely used for spore decontamination. As a consequence, spores that have defective coats because of mutation(s) or chemical de-coating are sensitized to these oxyhalogens and to many other types of chemicals, although not to all. Indeed, the coat plays only a minor role in spore resistance to chemicals such as $\mathrm{H}_{2} \mathrm{O}_{2}$, nitrous acid, acid and alkali, and DNA alkylating agents (Table 7). In a few cases, enzymes present in spore coats, superoxide dismutases (SODs catalyze the dismutation of superoxide, $\mathrm{O}_{2}{ }^{-}$, to $\mathrm{O}_{2}$ or to $\mathrm{H}_{2} \mathrm{O}_{2}$ ) and catalases (catalyze

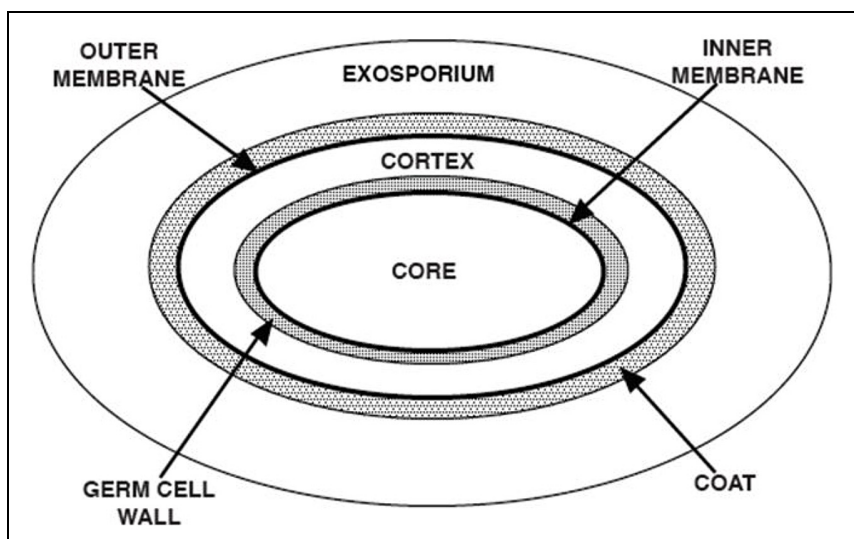

FIGURE 16 | Spore structure. The various layers of a typical spore are shown in schematic form, and the various spore layers are not drawn to scale. Note that the exosporium is not present in spores of all species. the disproportionation of $\mathrm{H}_{2} \mathrm{O}_{2}$ to $\mathrm{O}_{2}$ and $\mathrm{H}_{2} \mathrm{O}$ ), have been shown to play roles in spore resistance to some oxidizing agents, both in vitro and in in vivo-like environments (Henriques and Moran, 2007; Cybulski et al., 2009; McKenney et al., 2013).

Beneath the spore coat is found the outer membrane, which is a critical element in spore formation. While it is possible that the outer membrane is a permeability barrier in dormant spores (Gerhardt and Black, 1961; Rode et al., 1962), this role is not clear, and there are no mutants that specifically affect the spore's outer membrane. The outer membrane is also lost either partially or completely in spores with defective coats, and the outer membrane is also removed by chemical de-coating treatments (Buchanan and Neyman, 1986). In general, the outer membrane specifically is thought not to play a major role in spore resistance properties, but it is actually difficult to separate the roles of the outer membrane and coat in determining spore resistance properties.

Under the outer membrane are two layers of peptidoglycan (PG); first, the large spore cortex, then the thinner germ cell wall that comprises the minority of total spore PG (Popham, 2002). The germ cell wall PG has a structure that appears identical to that of growing cell wall PG structure, and cortex PG has a structure similar to that of the germ cell wall PG, but with several cortexspecific modifications. As a consequence, in the process of spore germination, cortex-lytic enzymes (CLEs) degrade cortex PG, while leaving the germ cell wall intact and allowing this structure to form the cell wall of the outgrowing spore (Setlow, 2013). The cortex's main role in spore resistance appears to be to maintain and possibly help establish the extremely low water content in the central spore core $(25-50 \%$ of wet $\mathrm{wt}$ ) that is crucial in spore resistance to wet heat (Table 7) and probably in spore dormancy (see below). There are a number of $B$. subtilis mutants that affect cortex PG structure. Some changes in cortex PG are associated with changes in spore wet heat resistance, and, in some cases, changes in cortex PG are associated with changes in spore core water content (Zhang et al., 2012).

Under the germ cell wall is found the second spore membrane called the inner membrane (IM). This IM has a phospholipid and fatty acid composition similar to the plasma membrane of the growing or sporulating cell (Griffiths and Setlow, 2009). However, lipid probes in the IM are immobile, suggesting the IM is not as fluid as membranes in growing cells, although IM fluidity is restored when spores complete germination and the core expands (Cowan et al., 2004). This expansion takes place in the absence of any ATP synthesis as the volume enclosed by the IM increases more than twofold. As with IM lipid mobility, IM permeability also rises dramatically, when the IM enclosed volume increases during spore germination. The low permeability of the dormant spore IM appears to contribute significantly to spore resistance to hydrophilic chemicals, as changes in dormant spore IM permeability due to changes in sporulation conditions, primarily temperature, parallel changes in IM permeability (Cortezzo and Setlow, 2004). It has been suggested that the IM is held in some sort of compressed state in the dormant spore, and this suggested structure is consistent with the extremely low permeability of the IM observed in dormant spores, even to a hydrophobic molecule 
such as methylamine, and perhaps even to water (Setlow and Setlow, 1980; Swerdlow et al., 1981; Cortezzo and Setlow, 2004; Sunde et al., 2009; Ghosal et al., 2010; Kaieda et al., 2013; Kong et al., 2013). Unfortunately, the precise structure of dormant spores' IM and how this structure influences IM permeability are still not clear. This is important information, because a number of key proteins in spore germination are in the IM (Setlow and Johnson, 2012; Setlow, 2013), and IM properties will most likely influence the function of these germination proteins.

The final spore layer is the central core, the site of spore DNA, RNA, and most spore enzymes. As noted above, the core has low water content, and this undoubtedly is the reason that soluble, mobile and active proteins in growing cells are immobile and inactive in the spore core (Gerhardt and Marquis, 1989; Setlow, 1994; Cowan et al., 2003). Indeed, while the dormant spore core has enzymes such as catalases and superoxide dismutases that play major roles in the resistance of growing cells to oxidizing agents, these enzymes play no role in dormant spore resistance, presumptively because they are inactive in the environment of the dormant spore core (Setlow, 2006; Leggett et al., 2012). The low core water content is most likely the major factor in spore resistance to wet heat (Gerhardt and Marquis, 1989). There are also at least three other unique spore core features to consider. First, the core $\mathrm{pH}$ is $\sim 1.5$ units lower than the $\mathrm{pH}$ in a growing cell or in the mother cell compartment of the sporulating cell (Setlow and Setlow, 1980). The importance of this low core $\mathrm{pH}$ in spore resistance is not clear, since the core $\mathrm{pH}$ can be elevated 1.5 units with no effects on spore dormancy or resistance (Swerdlow et al., 1981). However, the decrease in spore core $\mathrm{pH}$ during sporulation appears to be important in the modulation of enzyme activity in the developing spore late in sporulation (Setlow, 1994). Enzymes that are modulated in this way include the zymogen of the GPR protease that auto-activates at a low $\mathrm{pH}$, and phosphoglycerate mutase [catalyzes the interconversion of 3phosphoglycerate (3-PGA) to 2-phosphoglycerate] that becomes much less active at $\mathrm{pH} \sim 6.3$, thus causing the accumulation of a large amount of 3-PGA in the dormant spore (IlladesAguiar and Setlow, 1994; Setlow, 1994). This 3-PGA depot is rapidly catabolized to generate ATP in the first minutes of spore germination, during which core $\mathrm{pH}$ rises to $\sim 7.8$ and core water content rises to $\sim 80 \%$ of wet wt (Setlow and Johnson, 2012; Setlow, 2013).

A second unique feature of the spore core is the high level ( $\sim 20 \%$ of core dry wt) of pyridine-2,6-dicarboxylic acid [dipicolinic acid (DPA)], which exists as a 1:1 chelate with divalent cations, predominantly $\mathrm{Ca}^{2+}$ (CaDPA; Gerhardt and Marquis, 1989; Setlow, 2006; Setlow and Johnson, 2012). DPA is made in the mother cell compartment of the sporulating cell, and the accumulation of CaDPA in the core late in sporulation plays a significant role in reducing spore core water content (Paidhungat et al., 2000). CaDPA in the core also has significant affects on spore DNA photochemistry, and thus CaDPA accumulation in the core alters spore resistance to UV radiation, but actually sensitizes DNA to UV radiation at some wavelengths (Setlow, 2001, 2007b). While the spores' huge CaDPA depot is stable for long periods in spores suspended in water even at relatively high temperatures $\left(75-80^{\circ} \mathrm{C}\right.$ for $B$. subtilis spores), the spores' entire CaDPA depot is released rapidly in the first minutes of spore germination (Setlow, 2013). In addition, treatment with a number of oxidizing agents alters spores in some fashion such that their CaDPA depot is released completely even at $75^{\circ} \mathrm{C}$ (Cortezzo et al., 2004).

Another notable unique feature of the spore core is the saturation of spore DNA with a group of novel small DNA-

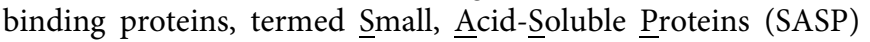
of the $\alpha / \beta$-type, so named because the two major proteins of this type in B. subtilis were initially termed SASP- $\alpha$ and SASP- $\beta$ (Setlow, 2001, 2007b). The amino acid sequences of these $\sim 60-$ 75 residue proteins are unique and extremely well-conserved both within and across spore forming species, including members of both Clostridiales and Bacillales. The $\alpha / \beta$-type SASP play major roles in protecting spore DNA against UV radiation $(\sim 260 \mathrm{~nm}$ ) by changing DNA structure from the B-form to an A-like form in which the UV photoproducts formed in growing cell DNA, including cyclobutane pyrimidine dimers and 6-4 photoproducts between adjacent pyrimidines, are not generated, and some of the latter UV lesions are extremely mutagenic and thus potentially lethal. In contrast, with $\alpha / \beta$-type SASP saturated DNA the major UV photoproduct generated by $\sim 260 \mathrm{~nm}$ radiation is a novel thymine-thymine adduct initially called the spore photoproduct (SP), and spores have a number of enzymes that repair SP in a relatively error-free manner. Thus $\alpha / \beta$-type SASP are a major factor in spore resistance to UV radiation and also to $\gamma$-radiation, although repair of DNA damage in spore outgrowth is also important (Setlow, 2001, 2007b; Moeller et al., 2014). The $\alpha / \beta$-type SASP also protect spore DNA against other types of damage, particularly depurination by wet and dry heat, and also against a number of genotoxic chemicals, including nitrous acid and formaldehyde (Setlow, 2006). The structure of a complex of an $\alpha / \beta$-type SASP bound to a short DNA fragment in conjunction with modeling studies based on this structure have elucidated the causes of these effects of $\alpha / \beta$-type SASP on DNA properties at the atomic level (Lee et al., 2008).

The $\alpha / \beta$-type SASP are degraded in the first minutes of spore germination and outgrowth (Setlow, 1994, 2013) in a process initiated by an endoprotease termed GPR that is specific for a conserved sequence found in all $\alpha / \beta$-type SASP. Oligopeptides generated by GPR cleavage are then degraded rapidly to free amino acids that are re-utilized by the outgrowing spore for metabolism and protein synthesis. Spores in which $\alpha / \beta$-type SASP are not degraded rapidly following spore germination, either because GPR is inactive or because an $\alpha / \beta$-type SASP binds too tightly to DNA, exhibit slow outgrowth and in some cases decreased viability (Setlow, 1994; Hayes and Setlow, 2001).

\subsection{Mechanisms of Spore Killing}

Work primarily with $B$. subtilis spores, and some with spores of other species (Setlow, 2006; Setlow et al., 2014), has identified five different mechanisms for killing of spores by various agents (Table 7). These are: (1) DNA damage; (2) damage to the spores' IM; (3) damage to some essential spore core protein; (4) explosive 
rupture of the dormant spores' IM; and (5) destruction of one or more spore components that are essential for spore germination. It is important to note that spores apparently inactivated by the last mechanism may not actually be dead, but just cannot return to active growth, since spore germination is blocked. There are a number of examples of spores that appear dead because they can't germinate, but return to life, when assisted in spore germination, generally by provision with a lytic enzyme that can degrade spores' PG cortex (Setlow et al., 2002; ParedesSabja et al., 2009a,b; Burns et al., 2010). This has been observed with spores that are apparently inactivated by treatment with chemical agents that either remove and/or inactivate enzymes in spores' outer layers such as CLEs and/or proteases that can activate CLE zymogens in spores of Clostridium species. Thus, it is crucial to ensure that a spore killing regimen has not simply rendered spores incapable of germinating, such that the treated spores cannot be revived by artificial germination treatments; a number of tests have been used to demonstrate this (Setlow et al., 2014).

Among the other four methods of spore killing, the rarest is probably explosive rupture of the dormant spores' outer layers. This phenomenon has only been seen with spores incubated in rather high concentrations of strong mineral acids such as $\mathrm{HCl}$ or $\mathrm{HNO}_{3}$ (Setlow et al., 2002; Setlow, 2006). As would be expected, UV and $\gamma$-radiation kill spores largely by DNA damage, since loss of DNA repair capacity greatly decreases spore resistance to these treatments, and survivors of these radiation treatments also accumulate high levels of mutations. A number of genotoxic chemicals, including nitrous acid and formaldehyde, also kill spores by DNA damage, as does dry heat, which generates significant levels of abasic sites in DNA. However, the potentially genotoxic agent, $\mathrm{H}_{2} \mathrm{O}_{2}$, does not kill spores by DNA damage, because of the strong protection of DNA against $\mathrm{H}_{2} \mathrm{O}_{2}$ damage by the $\alpha / \beta$-type SASP.

While the mechanisms of spore killing and of spore resistance are known for many of the agents used to kill spores in applied settings - wet heat, radiation, chemicals such as hypochlorite or chlorine dioxide - there is a lack of definitive studies on the exact mechanisms of spore killing by and resistance to high hydrostatic pressure (HP) and various types of plasmas. In the case of $\mathrm{HP}$, treatments at HP $\approx 400-700 \mathrm{MPa}$ (levels proposed for food processing) do not efficiently kill spores, unless accompanied by elevated temperature $\left(T=90-121^{\circ} \mathrm{C}\right)$. Spore killing by $\mathrm{HP}$ treatments takes place in (at least) two steps; first, spores are germinated by the $\mathrm{HP}$, then the much less resistant germinated spores are killed at the elevated temperatures at which $\mathrm{HP}$ treatments are carried out.

Generally, moderate HPs $\left(100-350 \mathrm{MPa}, T=37^{\circ} \mathrm{C}\right)$ trigger germination by activating the same GRs that trigger spore germination with nutrients, while $\mathrm{HPs}$ of $400-900 \mathrm{MPa}$ $\left(T \geq 50^{\circ} \mathrm{C}\right)$ appear to directly open the channel through which $\mathrm{CaDPA}$ is normally released during germination (Setlow, 2007a; Reineke et al., 2013a,b). Recent studies have indicated that HP treatments in the regime $P=550-692 \mathrm{MPa}$ and $T=75-112^{\circ} \mathrm{C}$ induce spore activation (potentiate spores for germination), and this can even increase apparent spore titers (Luu et al., 2015).
This latter effect has been seen with spores of the model spore former, B. subtilis, and also with spores of B. amyloliquefaciens, a suggested surrogate for Clostridium botulinum spores in HP studies (Margosch et al., 2004; Sevenich et al., 2014). Other recent work (Kong et al., 2014) with B. subtilis spores has shown that: (i) $140 \mathrm{MPa} \mathrm{HP}$ treatments as short as $10 \mathrm{~s}$ can commit spores to germinate for up to $10 \mathrm{~min}$ during holding at atmospheric pressure; and (ii) almost all spores go on to germinate over $>45$ min after a $10 \mathrm{~s} 140 \mathrm{MPa}$ HP treatment during holding at $1 \mathrm{MPa}$, a pressure that alone does not induce germination. These latter findings indicate that at least some of the effects of $140 \mathrm{MPa}$ of HP that can lead to spore germination are reversible, and thus the reversible events take place before events that irreversibly commit spores to germinate. It will be of interest to examine these same phenomena in spores exposed to HPs $\geq 500 \mathrm{MPa}$ (the HP that opens channels for CaDPA release in B. subtilis spores).

In the case of cold plasma, when significant levels of UV photons are associated with a particular type of plasma, there is evidence that these plasmas kill spores by DNA damage and $\alpha / \beta$-type SASP and DNA repair are important in spore resistance to such plasmas (Roth et al., 2010; Yardimci and Setlow, 2010; Klämpfl et al., 2012; van Bokhorst-van de Veen et al., 2015). For plasmas that have minimal associated UV photons, mechanisms of spore killing and resistance are less clear. There is certainly evidence that plasmas with oxygen in the feed gas can cause significant physical damage to spores by etching the spores' outer layers. However, it is likely that this physical damage is not what actually kills spores, and research is needed to establish definitively mechanisms of spore killing by and resistance to various plasmas, including those that contain minimal levels of UV photons.

Surprisingly, wet heat treatment does not kill spores by DNA damage, even though the temperatures used for spore killing, $\geq 90^{\circ} \mathrm{C}$, might be expected to generate many abasic sites in DNA due to depurination. However, $\alpha / \beta$-type SASP protect DNA so well-against damage by wet heat that wet heat almost certainly kills spores by damage to one or more essential core proteins (Setlow, 2006; Coleman et al., 2007, 2010; Leggett et al., 2012). As might be expected, spores lacking the majority of their $\alpha / \beta$-type SASP, termed $\alpha^{-} \beta^{-}$spores, are more sensitive to wet heat, which kills $\alpha^{-} \beta^{-}$spores by DNA damage including depurination. Some peroxides (e.g., $\mathrm{H}_{2} \mathrm{O}_{2}$ ), also kill $\alpha^{-} \beta^{-}$spores by DNA damage, although they probably kill wild-type spores by damage to some core protein(s).

While some toxic chemicals kill spores either by DNA damage or damage to some spore core protein(s), many toxic chemicals used in the killing of spores, including chlorine dioxide $\left(\mathrm{ClO}_{2}\right)$, hypochlorite $\left(\mathrm{OCl}^{-}\right)$, and iodine, kill spores by damaging the spores' IM, such that the IM ruptures when the treated spores germinate (Cortezzo et al., 2004; Setlow, 2006; Leggett et al., 2012). Treatment with these agent(s) also seems to somehow alter the IM in dormant spores, such that: (i) the IM permeability increases dramatically; and (ii) the IM is less able to withstand a thermal stress, and DPA is released at much lower temperatures than corresponding untreated spores. Further indications of damage to spores by a number 
of oxidizing agents are that: (i) treated spores germinate quite slowly, even if some of the germinated spores do ultimately give rise to colonies upon plating; and (ii) recovery of colonies from such treated spores is extremely sensitive to increased salt concentrations in the recovery media. However, the nature of the damage affecting the spores' IM leading to these effects is not known.

\subsection{Summary}

The AFM methods discussed previously provide information complementary to the spore inactivation mechanism discussion above by visualizing and characterizing spore morphological, dimensional, and coat structural attributes, particularly in response to sterilization and/or decontamination treatments by gamma-irradiation or $\mathrm{ClO}_{2}$. For example, irradiation treatments induced pronounced morphological and structural differences compared with native spores, including loss of refractility, decreased size, and damage to spore internal structural integrity, which is consistent with, but not necessary revealing of, DNA damage, the primary mechanism of bacterial spore inactivation by $\gamma$-irradiation. It is also possible that the sterilization treatment by $\gamma$-irradiation is extensive and induces further structural damage to already-killed spores as additional post-mortem events. Interestingly, $\mathrm{ClO}_{2}$-treated spores showed similar height, morphology, and high-resolution spore coat architecture and topology compared to native, untreated spores. Such observations with AFM are consistent with the known mechanisms of spore inactivation by $\mathrm{ClO}_{2}$ by acting on the IM as mentioned above, such that $\mathrm{ClO}_{2}$-killed spores treatments retain refractility (phase-bright) and size, but falter during germination and are unable to grow out (Young and Setlow, 2003).

Atomic force microscopy measurements also showed the reversibility of a size transition in fully hydrated, dehydrated, and re-hydrated environments. AFM characterization also showed that spore size decreases in dehydrated environments (air versus water), most likely due to contraction of the spore core and/or cortex. In contradistinction, the spore coat is more intractable, not shrinking or expanding with dehydration or hydration, respectively, but providing some flexibility to accommodate internal volume changes of spores by surface folding and the formation of ridges in air-dried spores that are absent from the surface of fully hydrated spores. Such results are complementary to and consistent with the development of spore BIs mentioned above. The spore BIs tested a number of strains, doses $\left(\mathrm{ClO}_{2}\right.$ concentration $\times$ time profiles) and humid environments and found that $\% \mathrm{RH} \geq 70$ was needed presumptively to promote spore swelling and facilitate internalization of $\mathrm{ClO}_{2}$ molecules to effectuate spore inactivation and oxidizing proteins associated with the spore IM. It is absolutely essential for the sterilization of Ebola contaminated devices and equipment in that the spore BIs provide a full and reliable assay of sterilization, to prevent the spread of disease, protect international healthcare workers on the front lines of global public health crises, and to care for the afflicted and save lives. Thus, the complementary information provided through bacterial spore mechanistic studies, AFM morphological and structural characterization, and spore BI are needed to provide the full assurance that NSRDEC's novel decontamination technologies, to include the FDKs that operate at $70-90 \% \mathrm{RH}$ and $>7000 \mathrm{ppm} \mathrm{ClO}_{2}$, are achieving sterilization when deployed in global crises, and the results reported above provide science-based solutions that satisfy this mission with confidence.

\subsection{Conclusion}

Moving exciting research findings from the benchtop to the hands of the end-user as novel technologies is a paramount goal of Science and Technology (S\&T) for many government research and development (R\&D) facilities. The novel $\mathrm{ClO}_{2}$ decontamination technologies invented at NSRDEC serve as a model for successful federal research and development work, Technology Transfer, commercialization, and deployment for actual use in the field. In fact, this work began with basic research in the mechanisms of bacterial spore inactivation, then transitioned to early exploratory research and development work focused on the chemical reaction kinetics and mechanisms of $\mathrm{ClO}_{2}$ formation occurring through a unique chemical effector. Later development work consisted of inventions, validating efficacy, obtaining patents, and eventually transitioning to private industry through Technology Transfer for commercialization in the marketplace. This technology has become a COTS item that enables its recent culmination as FDKs deployed at clinical sites in West Africa for the sterilization of Ebola-contaminated medical devices at a time when concern of the Ebola crisis in those regions and the fears of the virus spreading internationally were at their highest.

Scientists at NIH/NIAID and USAMRIID (The U.S. Army Medical Research Institute of Infectious Diseases) adapted the COTS version of NSRDECs novel decontamination technologies and developed compact, lightweight, easy-to-carry FDKs for use by global public health organizations such as MSF, the WHO, Public Health Canada, NIH, and the U.S. government to improve hygienic conditions in remote clinics where little infrastructure existed by sterilizing medical equipment and help fight the spread of a deadly disease that cost thousands of lives and untold costs in medical expenses caring for the afflicted.

Natick Soldier RD\&E Center's novel decontamination technologies were readily available to help others meet and overcome the challenges and concerns of this international public health through $R \& D$ that strives for such preparedness. These novel technologies decontaminate microbes in myriad applications, such as rinses, sprays, and gas for fresh produce; food contact and handling surfaces; PPE; textiles used in clothing, uniforms, tents, and shelters; graywater; airplanes; surgical instruments; and hard surfaces in latrines, laundries, and deployable medical facilities.

One strength of NSRDECs novel decontamination technologies is that the mechanisms of bacterial spore inactivation by $\mathrm{ClO}_{2}$ and the use of spore bio-indicators for $\mathrm{ClO}_{2}$ in decontamination procedures have been investigated thoroughly at University of Connecticut Health Center, Lawrence 
Livermore National Laboratories, Children's Hospital of Oakland Research Institute, Stonehill College, and Brandeis University, making the fundamental science of $\mathrm{ClO}_{2}$ generation and decontamination well-understood, and NSRDECs technologies more assured and reliable. We have also reviewed mechanisms of bacterial spore inactivation by novel, emerging, and established non-thermal technologies for food preservation, such as HPP, irradiation, cold plasma, and chemical sanitizers, using an array of $B$. subtilis mutants to probe mechanisms of spore germination and inactivation, demonstrating that understanding the basic science allows the development of innovative technologies that can find solutions in diverse applications outside of the pasteurization and sterilization of foodstuffs.

\section{Acknowledgments}

We express our gratitude and appreciation to the US Army Natick Soldier RD\&E Center, to the Joint Science and Technology Office for Chemical and Biological Defense Integrated Protective Fabric System program (managed at NSRDEC), and to Mr. James M. Doona (Mathematician) for helpful discussions and Mr. Murphy C. Doona for counting spores.

Work carried out in the Setlow laboratory on spore resistance and killing has received generous support over many years from

\section{References}

Aieta, E. M., and Berg, J. D. (1986). A review of chlorine dioxide in drinking water treatment. J. Am. Water Works Assoc. 78, 62-72.

Anelich, L., and Moy, G. G. (2014). Ebola Virus Disease (EVD): Important Aspects for the Food Science and Technology Community. IUFoST Scientific Information Bulletin. Available at: http://www.iufost.org/iufostftp/IUFoST\%20SIB\%20 \%20-\%20Ebola\%20Virus\%20Disease\%20update\%201.pdf [accessed March 12, 2015].

Bruch, C. W. (1973). "Sterilization of plastics: toxicity of ethylene oxide residues," in Industrial Sterilization: International Symposium, eds G. B. Phillips and W. S. Miller (Amsterdam: Duke University Press), 49-77.

Buchanan, C. E., and Neyman, S. L. (1986). Correlation of penicillin-binding protein composition with different functions of two membranes in Bacillus subtilis forespores. J. Bacteriol. 165, 498-503.

Burns, D. A., Heap, J. T., and Minton, N. P. (2010). SleC is essential for germination of Clostridium difficile spores in nutrient-rich medium supplemented with the bile salt taurocholate. J. Bacteriol. 192, 657-664. doi: 10.1128/JB.01 209-09

Carroll, A. M., Plomp, M., Malkin, A. J., and Setlow, P. (2008). Protozoal digestion of coat-defective Bacillus subtilis spores produces "rinds" composed of insoluble coat protein. Appl. Environ. Microbiol. 74, 5875-5881. doi: 10.1128/AEM.01228-08

Chapman, J., Lee, W., Youkilis, E., and Martis, L. (1986). Animal model for ethylene oxide (EtO) associated hypersensitivity reactions. ASAIO Trans. 32, 482-485. doi: 10.1097/00002480-198609000-00019

Cléry-Barraud, C., Gaubert, A., Masson, P., and Vidal, D. (2004). Combined effects of high hydrostatic pressure and temperature for inactivation of Bacillus anthracis spores. Appl. Environ. Microbiol. 70, 635-637. doi: 10.1128/AEM.70.1.635-637.2004

Coleman, W. H., Chen, D., Li, Y.-Q., Cowan, A. E., and Setlow, P. (2007). How moist heat kills spores of Bacillus subtilis. J. Bacteriol. 189, 8458-8466. doi: 10.1128/JB.01242-07 the Army Research Office, the Defense Threat Reduction Agency, and the NIH.

The AFM work in the Malkin laboratory was performed under the auspices of the U.S. Department of Energy by Lawrence Livermore National Laboratory under Contract DE-AC5207NA27344 and supported by a grant from the Federal Bureau of Investigation and by Lawrence Livermore National Laboratory through Laboratory Directed Research and Development Grant 04-ERD-002. The authors are grateful to Marco Plomp for his critical contributions in the AFM characterization and data analysis.

Work in the Leighton laboratory was funded by The Defense Advanced Research Projects Agency (DARPA). We acknowledge with pleasure and gratitude the contributions of Katie Wheeler and Gordon Eggum to the study of $\mathrm{ClO}_{2}$ bioindicators.

The Natick Soldier Research, Development and Engineering Center is part of the U.S. Army Research, Development and Engineering Command, which has the mission to develop technology and engineering solutions for America's Soldiers.

RDECOM is a major subordinate command of the U.S. Army Materiel Command. AMC is the Army's premier provider of materiel readiness - technology, acquisition support, materiel development, logistics power projection, and sustainment - to the total force, across the spectrum of joint military operations. If a Soldier shoots it, drives it, flies it, wears it, eats it or communicates with it, AMC provides it.

Coleman, W. H., Zhang, P., Li, Y.-Q., and Setlow, P. (2010). Mechanism of killing of spores of Bacillus cereus and Bacillus megaterium by wet heat. Lett. Appl. Microbiol. 50, 507-514. doi: 10.1111/j.1472-765X.2010. 02827.x

Cortezzo, D. E., Koziol-Dube, K., Setlow, B., and Setlow, P. (2004). Treatment with oxidizing agents damages the inner membrane of spores of Bacillus subtilis and sensitizes spores to subsequent stress. J. Appl. Microbiol. 97, 838-852. doi: $10.1111 /$ j.1365-2672.2004.02370.x

Cortezzo, D. E., and Setlow, P. (2004). Analysis of factors that influence the sensitivity of spores of Bacillus subtilis to DNA damaging chemicals. J. Appl. Microbiol. 98, 606-617. doi: 10.1111/j.1365-2672.2004.02495.x

Cowan, A. E., Koppel, D. E., Setlow, B., and Setlow, P. (2003). A soluble protein is immobile in dormant spores of Bacillus subtilis but is mobile in germinated spores: implications for spore dormancy. Proc. Natl. Acad. Sci. U.S.A. 100, 4209-4214. doi: 10.1073/pnas.0636762100

Cowan, A. E., Olivastro, E. M., Koppel, D. E., Loshon, C. A., Setlow, B., and Setlow, P. (2004). Lipids in the inner membrane of dormant spores of Bacillus species are largely immobile. Proc. Natl. Acad. Sci. U.S.A. 101, 7733-7738. doi: 10.1073/pnas.0306859101

Curtin, M. A., Dwyer, S., Bukvic, D., Doona, C. J., and Kustin, K. (2014). Kinetics and mechanism of the reduction of sodium chlorite by sodium hydrogen ascorbate in aqueous solution at near neutral pH. Int. J. Chem. Kinet. 46, 216-219. doi: 10.1002/kin.20847

Curtin, M. A., Taub, I. A., Kustin, K., Sao, N., Duvall, J. R., Davies, K. I., et al. (2004). Ascorbate-induced oxidation of formate by peroxodisulfate: product yields, kinetics, and mechanism. Res. Chem. Intermed. 30, 647-661. doi: $10.1163 / 1568567041570384$

Cybulski, R. J., Sanz, P., Alem, F., Stibitz, S., Bull, R. L., and O’Brien, A. D. (2009). Four superoxide dismutases contribute to Bacillus anthracis virulence and provide spores with redundant protection against oxidative stress. Infect. Immun. 77, 271-285. doi: 10.1128/IAI.00515-08

Dauphin, L. A., Newton, B. R., Rasmussen, M. V., Meyer, R. F., and Bowen, M. D. (2008). Gamma irradiation can be used to inactivate Bacillus anthracis 
spores without compromising the sensitivity of diagnostic assays. Appl. Environ. Microbiol. 74, 4427-4433. doi: 10.1128/AEM.00557-08

Dolovich, J., Marshall, C. P., Smith, E. K. M., Shimizu, A., Pearson, F. C., Sugona, M. A., et al. (1984). Allergy to ethylene oxide chronic hemodyalysis patients. Artif. Organs 8, 334-337. doi: 10.1111/j.1525-1594.1984.tb04301.x

Doona, C. J., Feeherry, F. E., Setlow, P., Malkin, A. J., and Leighton, T. J. (2014). The portable chemical sterilizer (PCS), D-FENS, and D-FEND ALL: novel chlorine dioxide decontamination technologies for the military. J. Vis. Exp. 88, e4354. doi: $10.3791 / 4354$

Driks, A. (2003). The dynamic spore. Proc. Natl. Acad. Sci. U.S.A. 100, 3007-3009. doi: 10.1073 pnas.0730807100

Driks, A. (2009). The Bacillus anthracis spore. Mol. Aspects Med. 30, 368-373. doi: 10.1016/j.mam.2009.08.001

Feeherry, F. E., Munsey, D. T., and Rowley, D. B. (1987). Thermal inactivation and injury of Bacillus stearothermophilus spores. Appl. Environ. Microbiol. 53, $365-370$.

Foran, A. (2013). NSRDEC Patents Help Army into 'Top 100 Global Innovators.' Available at: http://www.army.mil/article/99816/ [accessed March 12, 2015].

Gerhardt, P. (1967). Cytology of Bacillus anthracis. Fed. Proc. 26, 1504-1517.

Gerhardt, P., and Black, S. H. (1961). Permeability of bacterial spores. II. Molecular variables affecting solute permeation. J. Bacteriol. 82, 750-760.

Gerhardt, P., and Marquis, R. E. (1989). "Spore thermoresistance mechanisms," in Regulation of Prokaryotic Development, eds I. Smith, R. A. Slepecky, and P. Setlow (Washington, DC: American Society for Microbiology), 43-63.

Ghosal, S., Leighton, T. J., Wheeler, K. E., Hutcheon, I. D., and Weber, P. K. (2010). Spatially-resolved characterization of water and ion incorporation in Bacillus spores. Appl. Environ. Microbiol. 76, 3275-3282. doi: 10.1128/AEM. 02485-09

Ghosh, S., Setlow, B., Wahome, P. G., Cowan, A. E., and Plomp, M. (2008). Characterization of spores of Bacillus subtilis that lack most coat layers. J. Bacteriol. 190, 6741-6748. doi: 10.1128/JB.00896-08

Griffiths, K., and Setlow, P. (2009). Effects of modification of membrane lipid composition on Bacillus subtilis sporulation and spore properties. J. Appl. Microbiol. 106, 2064-2078. doi: 10.1111/j.1365-2672.2009.04176.x

Han, Y., Floros, J. D., Linton, R. H., Nielsen, S. S., and Nelson, P. E. (2001). Response surface modeling for the inactivation of Escherichia coli O157:H7 on green peppers (Capsicum annuum L.) by chlorine dioxide gas treatments. J. Food Prot. 64, 1128-1131.

Han, Y., Guentert, A. M., Smith, R. S., Linton, R. H., and Nelson, P. E. (1999). Efficacy of chlorine dioxide gas as a sanitizer for tanks used for aseptic juice storage. Food Microbiol. 16, 53-61. doi: 10.1006/fmic.1998.0211

Hayes, C. S., and Setlow, P. (2001). An $\alpha / \beta$-type small, acid-soluble spore protein which has a very high affinity for DNA prevents outgrowth of Bacillus subtilis spores. J. Bacteriol. 183, 2662-2666. doi: 10.1128/JB.183.8.2662-2666.2001

Henriques, A. O., and Moran, C. P. (2007). Structure, assembly, and function of the spore surface layers. Ann. Rev. Microbiol. 61, 555-588. doi: 10.1146/annurev.micro.61.080706.093224

Horváth, A. K., Nagypál, I., Peintler, G., Epstein, I. R., and Kustin, K. (2003). Kinetics and mechanism of the decomposition of chlorous acid. J. Phys. Chem. A 107, 6966-6973. doi: 10.1021/jp027411h

Illades-Aguiar, B., and Setlow, P. (1994). Autoprocessing of the protease that degrades small, acid-soluble proteins of spores of Bacillus species is triggered by low $\mathrm{pH}$, dehydration and dipicolinic acid. J. Bacteriol. 176, 7032-7037.

Kaieda, S., Setlow, B., Setlow, P., and Halle, B. (2013). Mobility of core water in Bacillus subtilis spores by 2H NMR. Biophys. J. 105, 2016-2023. doi: 10.1016/j.bpj.2013.09.022

Kingsley, D. H., Vincent, E. M., Meade, G. K., Watson, C. L., and Fan, X. (2014). Inactivation of human norovirus using chemical sanitizers. Int. J. Food Microbiol. 171, 94-99. doi: 10.1016/j.ijfoodmicro.2013. 11.018

Klämpfl, T. G., Isbary, G., Shimizu, T., Li, Y.-F., Zimmerman, J. L., Stolz, W., et al. (2012). Cold atmospheric plasma and plasma sterilization against spores and other microorganisms of interest. Appl. Environ. Microbiol. 78, 5077-5082. doi: 10.1128/AEM.00583-12

Kong, L., Doona, C. J., Setlow, P., and Li, Y.-Q. (2014). Monitoring rates and heterogeneity of high pressure germination of Bacillus spores using phase contrast microscopy of individual spores. Appl. Environ. Microbiol. 80, 345-353. doi: 10.1128/AEM.03043-13
Kong, L., Setlow, P., and Li, Y.-Q. (2013). Direct analysis of water content and movement in single dormant bacterial spores using confocal Raman microspectroscopy. Anal. Chem. 85, 7094-7101. doi: 10.1021/ac400516p

Lee, K. S., Bumbaca, D., Kosman, J., Setlow, P., and Jedrzejas, M. J. (2008). Structure of a protein-DNA complex essential for DNA protection in spores of Bacillus species. Proc. Natl. Acad. Sci. U.S.A. 105, 2806-2811. doi: $10.1073 /$ pnas.0708244105

Leggett, M., McDonnell, G., Denyer, S., Setlow, P., and Maillard, J.-Y. (2012). Bacterial spore structures and their protective role in biocide resistance. J. Appl. Microbiol. 113, 485-499. doi: 10.1111/j.1365-2672.2012.05336.x

Lettman, S. F., Boltansky, H., Alter, H. J., Pearson, F. C., and Kaliner, M. A. (1986). Allergic reaction in healthy plateletpheresis donors caused by sensitization to ethylene oxide gas. N. Engl. J. Med. 315, 1192-1196. doi: 10.1056/NEJM198611063151904

Luu, S., Cruz-Mora, J., Setlow, B., Feeherry, F. E., Doona, C. J., and Setlow, P. (2015). The effects of heat activation on Bacillus spore germination, with nutrients or under high-pressure, with and without germination proteins. Appl. Environ. Microbiol. 81, 2927-2938. doi: 10.1128/AEM.00193-15

Lykins, B. W., Koffskey, W. E., and Patterson, K. S. (1994). Alternative disinfectants for drinking water treatment. J. Environ. Eng. 120, 745-758. doi: 10.1061/(ASCE)0733-9372(1994)120:4(745)

Malkin, A. J. (2011). "Resolving the high-resolution architecture, assembly and functional repertoire of bacterial systems by in vitro atomic force microscopy," in Life at the Nanoscale: Atomic Force Microscopy of Live Cells, ed. Y. Dufresne (Singapore: Pan Stanford Publishing), 71-99. doi: 10.1201/b11404-5

Malkin, A. J., and Plomp, M. (2010). "High-resolution architecture and structural dynamics of microbial and cellular system: insights from high-resolution in vitro atomic force microscopy," in Scanning Probe Microscopy of Functional Materials: Nanoscale Imaging and Spectroscopy, eds S. V. Kalinin and A. Gruverman (New York, NY: Springer), 39-68.

Margosch, D., Ehrmann, M. A., Gänzle, M. G., and Vogel, R. F. (2004). Comparison of pressure and heat resistance of Clostridium botulinum and other endospores in mashed carrots. J. Food Prot. 67, 2530-2537.

McKenney, P. T., Driks, A., and Eichenberger, P. (2013). The Bacillus subtilis endoscpore and functions of the multilayered coat. Nat. Rev. Microbiol. 11, 33-44. doi: 10.1038/nrmicro2921

Moeller, R., Raguse, M., Reitz, G., Okayasu, R., Li, Z., Klein, S., et al. (2014). Resistance of Bacillus subtilis spore DNA to lethal ionizing radiation damage relies primarily on spore core components and DNA repair, with minor effects of oxygen radical detoxification. Appl. Environ. Microbiol. 80, 104-109. doi: 10.1128/AEM.03136-13

Muttamara, S., Sales, C. I., and Gazali, Z. (1995). The formation of trihalomethane from chemical disinfectants and humic substances in drinking water. Water Supply 13, 105-117.

Paidhungat, M., Setlow, B., Driks, A., and Setlow, P. (2000). Characterization of spores of Bacillus subtilis which lack dipicolinic acid. J. Bacteriol. 182, 5505-5512. doi: 10.1128/JB.182.19.5505-5512.2000

Paredes-Sabja, D., Setlow, P., and Sarker, M. R. (2009a). The protease CspB is essential for initiation of cortex hydrolysis and DPA release during germination of spores of Clostridium perfringens. Microbiology 155, 3464-3472. doi: 10.1099/mic.0.030965-0

Paredes-Sabja, D., Setlow, P., and Sarker, M. R. (2009b). SleC is essential for cortex peptidoglycan hydrolysis during germination of spores of the pathogenic bacterium Clostridium perfringens. J. Bacteriol. 191, 2711-2720. doi: 10.1128/JB.01832-08

Plomp, M., Leighton, T. J., Wheeler, K. E., Hill, H. D., and Malkin, A. J. (2007a). In vitro high-resolution structural dynamics of single germinating bacterial spores. Proc. Natl. Acad. Sci. U.S.A. 104, 9644-9649. doi: 10.1073/pnas.0610626104

Plomp, M., McCaffery, J. M., Cheong, I., Huang, X., and Bettegowda, C. (2007b). Spore coat architecture of Clostridium novyi NT spores. J. Bacteriol. 189, 6457-6468. doi: 10.1128/JB.00757-07

Plomp, M., Leighton, T. J., Wheeler, K. E., and Malkin, A. J. (2005a). The highresolution architecture and structural dynamics of Bacillus spores. Biophys. J. 88, 603-608. doi: 10.1529/biophysj.104.049312

Plomp, M., Leighton, T. J., Wheeler, K. E., and Malkin, A. J. (2005b). Architecture and high-resolution structure of Bacillus thuringiensis and Bacillus cereus spore coat surfaces. Langmuir 21, 7892-7898. doi: 10.1021/la0 $50412 \mathrm{r}$ 
Plomp, M., Leighton, T. J., Wheeler, K. E., Pitesky, M. E., and Malkin, A. J. (2005c). Bacillus atrophaeus outer spore coat assembly and ultrastructure. Langmuir 21, 10710-10716. doi: 10.1021/la0517437

Plomp, M., and Malkin, A. J. (2009). Mapping of proteomic composition on the surfaces of Bacillus spores by atomic force microscopy. Langmuir 25, 403-409. doi: 10.1021/la803129r

Plomp, M., Monroe, C., Setlow, P., and Malkin, A. J. (2014). Architecture and assembly of the Bacillus subtilis spore coat. PLOS ONE 9:e108560. doi: 10.1371/journal.pone.0108560

Popham, D. L. (2002). Specialized peptidoglycan of the bacterial endospore: the inner wall of the lockbox. Cell. Mol. Life Sci. 59, 426-433. doi: 10.1007/s00018002-8435-5

Reineke, K., Mathys, A., Heinz, V., and Knorr, D. (2013a). Mechanisms of endospore inactivation under high pressure. Trends Microbiol. 21, 296-304. doi: 10.1016/j.tim.2013.03.001

Reineke, K., Schlumbach, K., Baier, D., Mathys, A., and Knorr, D. (2013b). The release of dipicolinic acid - the rate-limiting step of Bacillus endospore inactivation during the high pressure thermal sterilization process. Int. J. Food Microbiol. 162, 55-63. doi: 10.1016/j.ijfoodmicro.2012. 12.010

Rode, L. J., Lewis, C. W., and Foster, J. W. (1962). Electron microscopy of spores of Bacillus megaterium with special emphasis to the effects of fixation and thin sectioning. J. Cell. Biol. 13, 423-435. doi: 10.1083/jcb. 13.3.423

Rosenblatt, D. H., Rosenblatt, A. A., and Knapp, J. A. (1987). Use of Chlorine Dioxide Gas as a Chemosterilizing Agent. US patent\# 4681739.

Roth, S., Feichtinger, J., and Hertel, C. (2010). Characterization of Bacillus subtilis spore inactivation in low-pressure, low temperature gas plasma sterilization processes. J. Appl. Microbiol. 108, 521-531. doi: 10.1111/j.13652672.2009.04453.x

Setlow, B., Loshon, C. A., Genest, P. C., Cowan, A. E., Setlow, C., and Setlow, P. (2002). Mechanisms of killing of spores of Bacillus subtilis by acid, alkali and ethanol. J. Appl. Microbiol. 92, 362-375. doi: 10.1046/j.1365-2672.2002. 01540.x

Setlow, B., Parish, S., Zhang, P., Li, Y.-Q., Neely, W. C., and Setlow, P. (2014). Mechanism of killing of spores of Bacillus anthracis in a high temperature gas environment, and analysis of DNA damage generated by various decontamination treatments of spores of Bacillus anthracis, Bacillus subtilis and Bacillus thuringiensis. J. Appl. Microbiol. 116, 805-814. doi: 10.1111/jam.12421

Setlow, B., and Setlow, P. (1980). Measurements of the $\mathrm{pH}$ within dormant and germinated spores of Bacillus megaterium. Proc. Natl. Acad. Sci. U.S.A. 77, 2744-2746. doi: 10.1073/pnas.77.5.2474

Setlow, P. (1994). Mechanisms which contribute to the long-term survival of spores of Bacillus species. J. Appl. Bacteriol. 76, 49S-60S. doi: 10.1111/j.13652672.1994.tb04357.x

Setlow, P. (2001). Resistance of spores of Bacillus species to ultraviolet light. Environ. Mol. Mutagen. 38, 97-104. doi: 10.1002/em.1058

Setlow, P. (2006). Spores of Bacillus subtilis: their resistance to radiation, heat and chemicals. J. Appl. Microbiol. 101, 514-525. doi: 10.1111/j.13652672.2005.02736.x

Setlow, P. (2007a). "Germination of spores of Bacillus subtilis by high pressure," in High Pressure Processing of Foods, eds C. J. Doona and F. E. Feeherry (London: Blackwell Publishing), 15-40.

Setlow, P. (2007b). I will survive: DNA protection in bacterial spores. Trends Microbiol. 15, 172-180. doi: 10.1016/j.tim.2007.02.004

Setlow, P. (2013). When the sleepers wake: the germination of bacterial spores. J. Appl. Microbiol. 115, 1251-1268. doi: 10.1111/jam.12343

Setlow, P., Doona, C. J., Feeherry, F. E., Kustin, K., Sisson, D., and Chandra, S. (2009). "Enhanced safety and extended shelf-life of fresh produce for the military," in Microbial Safety of Fresh Produce, eds X. Fan, B. A. Niemira, C. J. Doona, F. E. Feeherry, and R. B. Gravani (Ames, IA: IFT Press/WileyBlackwell), 263-289.

Setlow, P., and Johnson, E. A. (2012). "Spores and their significance," in Food Microbiology: Fundamentals and Frontiers, 4th Edn, eds M. P. Doyle and R. Buchanan (Washington, DC: ASM Press).
Setlow, P., Liu, J., and Faeder, J. R. (2012). "Heterogeneity in bacterial spore populations," in Bacterial Spores: Current Research and Applications, ed. E. Abel-Santos (Norwich: Horizon Scientific Press).

Sevenich, R., Kleinstueck, E., Crews, C., Anderson, W., Pye, C., Riddellova, K., et al. (2014). High-pressure thermal sterilization: food safety and food quality of baby food purée. J. Food Sci. 79, M230-M237. doi: 10.1111/1750-3841.12345

Simpson, G. D., Miller, R. F., Laxton, G. D., and Clements, W. R. (1993). “A focus on chlorine dioxide: the "ideal" biocide," in Proceedings of the Volume, Annual NACE Corrosion Conference 93, Paper No. 472, New Orleans, LA. Available at: http://www.clo2.gr/en/pdf/secure/chlorinedioxideidealbiocide.pdf [accessed March 18, 2015].

Stubblefield, J. M., and Newsome, A. L. (2015). Potential biodefense model applications for portable chlorine dioxide gas production. Health Secur. 13, 20-28. doi: 10.1089/hs.2014.0017

Sunde, E. P., Setlow, P., Hederstedt, L., and Halle, B. (2009). The physical state of water in bacterial spores. Proc. Natl. Acad. Sci. U.S.A. 106, 19334-19339. doi: 10.1073/pnas.0908712106

Swerdlow, B. M., Setlow, B., and Setlow, P. (1981). Levels of $\mathrm{H}^{+}$and other monovalent cations in dormant and germinating spores of Bacillus megaterium. J. Bacteriol. 148, 20-29.

van Bokhorst-van de Veen, H., Xie, H., Esveld, E., Abee, T., Mastwijk, H., and Groot, M. N. (2015). Inactivation of chemical and heat-resistant spores of Bacillus and Geobacillus by nitrogen cold atmospheric plasma evokes distinct changes in morphology and integrity of spores. Food Microbiol. 45, 26-33. doi: 10.1016/j.fm.2014.03.018

Westphal, A. J., Price, P. B., Leighton, T. J., and Wheeler, K. E. (2003). Kinetics of size changes of individual Bacillus thuringiensis spores in response to changes in relative humidity. Proc. Natl. Acad. Sci. U.S.A. 100, 3461-3466. doi: $10.1073 /$ pnas.232710999

World Health Organization [WHO]. (2014). Ebola Virus Disease. Available at: http://www.who.int/mediacentre/factsheets/fs103/en/ [accessed March 12, 2015].

World Health Organization [WHO]. (2015a). 2014 Ebola Outbreak in West Africa - Case Counts. Available at: http://www.cdc.gov/vhf/ebola/outbreaks/ 2014-west-africa/case-counts.html [accessed March 23, 2015].

World Health Organization [WHO]. (2015b). The Five Keys to Safer Food Programme. Available at: http://www.who.int/mediacentre/factsheets/fs103/en/ [accessed March 12, 2015].

Yardimci, O., and Setlow, P. (2010). Plasma sterilization: opportunities and microbial assessment strategies in medical device manufacturing. IEEE Trans. Plasma Sci. 38, 973-981. doi: 10.1109/TPS.2010.2041674

Young, S. B., and Setlow, P. (2003). Mechanisms of killing of Bacillus subtilis spores by hypochlorite and chlorine dioxide. J. Appl. Microbiol. 95, 54-67. doi: 10.1046/j.1365-2672.2003.01960.x

Zhang, P., Thomas, S., Li, Y.-Q., and Setlow, P. (2012). Effects of cortex peptidoglycan structure and cortex hydrolysis on the kinetics of $\mathrm{Ca}^{2+}$ dipicolinic acid release during Bacillus subtilis spore germination. J. Bacteriol. 194, 646-652. doi: 10.1128/JB.06452-11

Conflict of Interest Statement: Christopher J. Doona, Florence E. Feeherry and Kenneth Kustin, as inventors from the U.S. Army Natick Soldier RD\&E Center, receive royalties for patented technologies licensed to ClorDiSys Solutions, Inc. and used in the Field Decontamination Kits. The other authors declare that the research was conducted in the absence of any commercial or financial relationships that could be construed as a potential conflict of interest.

At least a portion of this work is authored by Drs. Christopher J. Doona, Florence E. Feeherry, Kenneth Kustin, Gene G. Olinger and Alexander J. Malkin on behalf of the U.S. Government and, as regards Drs. Doona, Feeherry, Kustin, Olinger and Malkin and the U.S. Government, is not subject to copyright protection in the United States. Foreign and other copyrights may apply. This is an open-access article distributed under the terms of the Creative Commons Attribution License (CC BY). The use, distribution or reproduction in other forums is permitted, provided the original author(s) or licensor are credited and that the original publication in this journal is cited, in accordance with accepted academic practice. No use, distribution or reproduction is permitted which does not comply with these terms. 